\title{
Clock genes and their genomic distributions in three species of salmonid fishes: Associations with genes regulating sexual maturation and cell cycling
}

Marion I Paibomesai ${ }^{1}$, Hooman K Moghadam,2, Moira M Ferguson' ${ }^{1}$, Roy G Danzmann ${ }^{1 *}$

\begin{abstract}
Background: Clock family genes encode transcription factors that regulate clock-controlled genes and thus regulate many physiological mechanisms/processes in a circadian fashion. Clock1 duplicates and copies of Clock3 and NPAS2-like genes were partially characterized (genomic sequencing) and mapped using family-based indels/ SNPs in rainbow trout (RT)(Oncorhynchus mykiss), Arctic charr (AC)(Salvelinus alpinus), and Atlantic salmon (AS) (Salmo salar) mapping panels.

Results: Clock1 duplicates mapped to linkage groups RT-8/-24, AC-16/-13 and AS-2/-18. Clock3/NPAS2-like genes mapped to RT-9/-20, AC-20/-43, and AS-5. Most of these linkage group regions containing the Clock gene duplicates were derived from the most recent $4 R$ whole genome duplication event specific to the salmonids. These linkage groups contain quantitative trait loci (QTL) for life history and growth traits (i.e., reproduction and cell cycling). Comparative synteny analyses with other model teleost species reveal a high degree of conservation for genes in these chromosomal regions suggesting that functionally related or co-regulated genes are clustered in syntenic blocks. For example, anti-müllerian hormone (amh), regulating sexual maturation, and ornithine decarboxylase antizymes (oaz1 and oaz2), regulating cell cycling, are contained within these syntenic blocks.

Conclusions: Synteny analyses indicate that regions homologous to major life-history QTL regions in salmonids contain many candidate genes that are likely to influence reproduction and cell cycling. The order of these genes is highly conserved across the vertebrate species examined, and as such, these genes may make up a functional cluster of genes that are likely co-regulated. CLOCK, as a transcription factor, is found within this block and therefore has the potential to cis-regulate the processes influenced by these genes. Additionally, clock-controlled genes (CCGs) are located in other life-history QTL regions within salmonids suggesting that at least in part, transregulation of these QTL regions may also occur via Clock expression.
\end{abstract}

\section{Background}

Rhythms in reproductive development, physiology, and behavior are found ubiquitously in organisms including prokaryotes, plants, fungi, and animals. Life-history events are temporally organized throughout the lifetime of an organism, which suggests that there is a timekeeping mechanism that is regulating these events. Daily biological rhythms ( 24 hour cycle) are generated at the

\footnotetext{
* Correspondence: rdanzman@uoguelph.ca

'Department of Integrative Biology, University of Guelph, Guelph, Ontario, N1G 2W1, Canada

Full list of author information is available at the end of the article

molecular level through autoregulatory positive and negative feedback loops of the core clock genes (e.g. Clock, bmal1, Period, Rev-Erbo, Cryptochrome, Rora). CLOCK or NPAS2 (Neuronal PAS-domain) proteins form heterodimers with BMAL1 (Brain and Muscle ARNT-like) proteins (CLOCK:BMAL1 and NPAS2: BMAL1) which activate transcription of Period, Cryptochrome, Rev-erb $\alpha$ and Rora genes by binding to E-box motifs (CACGTG) in their promoter regions. PERIOD and CRYPTOCHROME proteins form complexes that act as feedback inhibitors to repress the transcriptional action of CLOCK:BMAL1 heterodimers. Two E-box 
activated orphan nuclear receptor proteins REV-ERB $\alpha$ and RORA, inhibit and activate transcription of bmall, respectively, by binding to the retinoid orphan receptor elements (RORE) in the promoter region of bmall (see [1] for a review). Because so many processes display circadian rhythms, the clock genes have been targeted as candidate genes with pleiotropic effects.

Disruption of circadian rhythm may have broad consequences at the molecular level, as previous studies indicate that $2 \%$ to $10 \%$ of all mammalian genes display circadian oscillation [2,3]. The expression of some of these genes is regulated by Clock exclusively, and these genes are called clock-controlled genes (CCGs). Clock encodes for a bHLH (basic-helix-loop-helix)-PAS (Period-Arylhydrocarbon receptor nuclear translocatorsingle minded) domain containing transcription factor which activates the transcription of CCGs. CLOCK acts as a histone acetyltransferase (HAT) to promote chromatin modifications in the promoter regions of these genes [4], and these genes in turn influence many physiological mechanisms downstream.

Clock genes are of interest as candidate genes that control life-history traits across different organisms because their allelic variation has been associated with reproductive traits in many organisms. For instance, Drosophila males with loss-of function for Clk (Clock) released less sperm than wild-types, thereby reducing reproductive fitness [5]. In female mice (Mus musculus), Clock mutations resulted in aberrant estrous cycles, subfertility [6], and higher pregnancy failure rates when compared to wild-type mice [7]. In salmonids, the Clock gene has been localized to genomic regions that influence reproductive events. Leder et al. [8] localized a copy of the Clock gene to a quantitative trait locus (QTL) region that explained 20\% - 50\% (dependent upon parental contribution) of the variation in spawning dates of female rainbow trout (Oncorhynchus mykiss). Also, O'Malley et al. [9] identified variant copies (alleles) of the Clock gene that differed significantly in frequency between fall vs. spring spawning Chinook salmon (Oncorhynchus tshawytscha). Because of the temporal nature of processes such as folliculogenesis, estrous cycles, and spermatogenesis, it is suggested that these processes are regulated by the Clock genes.

Similar to Clock, anti-müllerian hormone ( $a m h)$ (a member of the transforming growth factor beta protein super family) has purported effects on reproductive events in mammals and various fish species. In rats, $\mathrm{AMH}$ has been shown to inhibit cAMP activity and prevent or severely reduce follicle stimulating hormone (FSH) activation of Cyp19a1, an aromatase responsible for the conversion of androgens to estrogens [10]. In mammals, amh expression in the testes causes the regression of the Müllerian ducts, which are precursors of fallopian tubes and the uterus in the female reproductive system. Besides its role in sex determination early in life, amh plays a role in both female and male gonad development and maintenance [11,12]. The Müllerian ducts in females eventually lose sensitivity to $\mathrm{AMH}$ and the ovarian granulosa cells express $\mathrm{AMH}$ which inhibits the expression of Cyp19a1 and luteinizing hormone $(\mathrm{LH})$ receptors which in turn, negatively regulates folliculogenesis $[13,14]$. In males, amh activity prevents Leydig cell formation and steroidogenic enzyme production therefore inhibiting testes development [14]. amh expression in Sertoli cells in immature testes was also found to prevent spermatogenesis in mammals [15].

Sexual determination across the fishes is not solely dependent on genetic factors and the role of genetics in this process is not as clear as seen in mammals. amhlike genes have been described in some teleost species including, Japanese eel (Anguilla japonica) (BAB93107), Japanese flounder (Paralichthys olivaceus) (BAD37138), zebrafish (Danio rerio) and Atlantic salmon (Salmo salar) (AAU85130; AY722411; cluster TC149876 [16]). Examination of the expression patterns of amh in zebrafish [17], Japanese flounder [18], and Japanese eel [19], revealed sexually dimorphic expression patterns in juveniles as seen in mammals. In zebrafish, it was also shown that $a m h$ expression was present in both undifferentiated testes and ovaries later in development similar to what is seen in mammals [17]. As in mammals, Miura et al. [19] demonstrated that $a m h$ expression inhibited spermatogenesis. Similarly, in Atlantic salmon, amh levels appear to decrease rapidly at the onset of sexual maturation [20], and gene expression levels have also been reported to be several-fold higher in immature Atlantic salmon with a dramatic decrease seen in fish undergoing sexual maturation [21]. This evidence suggests that amh orthologs have similar roles across species. However, in contrast to this, amh expression was not detected in adult Japanese flounder ovaries [18]. Also, no sexually dimorphic expression of $a m h$ was observed in juvenile medaka (Oryzias latipes) [22]. In fact, within the Sertoli cells of adult medaka testes, high levels of amh expression were observed during spermatogenesis [22]. Although the function of AMH is less clearly understood in fishes, it does appear that differential expression of this gene is associated with differentiated sexual states in fishes.

Any research that investigates the molecular architecture of traits in vertebrates should take into consideration the past duplication events in this lineage. In humans (Homo sapiens) and mice, Clock and NPAS2 are two known paralogs which are related by the $2 \mathrm{R}$ genome duplication event [23]. Zebrafish and fugu (Takifugu rubripes) are known to have three copies of the Clock-family genes (Clock1, Clock3, NPAS2). Tetraodon 
(Tetraodon nigroviridis) has Clock1 and Clock3 genes, while medaka and stickleback (Gasterosteus aculeatus) have Clock1 and NPAS2 genes [23]. Clock1 and Clock3 are duplicates that resulted from the third round of whole genome duplication that occurred within the rayfinned fish lineage prior to the radiation of the teleost fishes (approximately $300 \mathrm{Mya}=3 \mathrm{R}$ hypothesis) [23]. An additional round of whole genome duplication (4R hypothesis) occurred in the salmonid lineage approximately 25 to 100 Mya [24], therefore we expect that for a single gene in most teleosts, gene duplicates may be found in the salmonids. Homeologs, which are chromosomal segments that arose from the most recent whole genome duplication events, have been previously identified in rainbow trout, Atlantic salmon, and Arctic charr (Salvelinus alpinus) [25,26]. Clock1 duplicates (homeologs) have also been identified in the Chinook salmon genome [27], supporting the 4R hypothesis. However, only singleton copies of $a m h$ have been identified in human, mouse, zebrafish, medaka, stickleback and the pufferfishes genomes, suggesting that there may be no functional duplicates in tetrapods, or even the ray-finned fishes. Currently, only a single amh copy has been identified in rainbow trout [28], however one may expect there to be a second copy due to the $4 R$ duplication event.

This study details the findings on the genetic mapping of Clock and amh gene copies in three species of salmonid fishes. It was predicted that if duplicates of the Clock-family and amh genes occurred within these salmonid genomes then they should map to previously identified homeologous regions. Also considering the putative role of these genes in influencing life-history traits it was predicted that they should be located in the genomic regions where life-history quantitative trait loci (QTL) have been found in salmonids. Therefore linkage group locations were compared to previously identified QTL for life-history traits, such as female spawning date, maturation time, and developmental rate in rainbow trout, Atlantic salmon, and Arctic charr. As anticipated, Clock-family and $a m h$ gene copies were co-localized to major life-history QTL regions in these salmonid fishes. Duplicated Clock copies occurred within the same syntenic cluster as $a m h$ and comparative synteny analyses of other genes upstream and downstream to this region identified several other major genes that may be involved in sexual reproduction and cell cycling. This suggests that Clock genes may localize within a 'reproductive controlling block' in vertebrate genomes.

\section{Results and Discussion}

\section{Characterization of Clock genes}

Analyses of partial Clock1 sequence data suggests that duplicates exist in the rainbow trout (OmyClock1a and
OmyClock1b) genome while only single copies were identified in Arctic charr (SalClock1b) and Atlantic salmon (SsaClock1b) genomes. For OmyClock1a, 4 exons were identified that were orthologous to Otsclock1a exons 15 to 18 from the $3^{\prime}$ end. Sequencing data for five exons similar to the 3 ' end of DreClock 1 was obtained for SsaClock1b ranging from exons 14 to 18 , and 6 exons for OmyClock $1 b$ and SalClock1b ranging from exons 14 to 19 (Figure 1.). As seen in Chinook salmon [27], distinct Clock1 $a$ and Clock1b sequence duplicates are evident in the rainbow trout genome, however, sequence data confirming independent Clock1a orthologs were not obtained from the Atlantic salmon and Arctic charr genomes. Mapping data, however, indicates that Clock1 duplicates do exist in Atlantic salmon and Arctic charr (discussed later), suggesting that sequence divergence between these two isoforms may be minimal in these two species.

The nucleotide sequence of the Clock1 duplicates, OmyClock $1 a$ and OmyClock1b, in rainbow trout were $64 \%$ identical. Coding sequences of OmyClock1a and OmyClock $1 b$ shared $90 \%$ identity which was analogous to what was seen for OtsClock1a and OtsClock1b comparisons (90\%) [27]. The genomic Clock1b sequences from all three salmonid species were compared, and OmyClock1b, SalClock1b and SsaClock1b were approximately $97 \%$ similar to each other. The coding sequences of OmyClock $1 b$ compared to $\neg S s a C l o c k 1 b$ and SalClock $1 b$ were greater than $98 \%$ identical. The pairwise comparisons suggest that orthologous copies among species are more similar to one another than the paralogous duplicates within species, suggesting a divergence predating the speciation events within the lineage. Similar observations have been made for other gene duplicates in the salmonids $[29,30]$.

The 64\% identity between OmyClock1a and OmyClock1b was, however, unexpectedly low compared to other paralogous genes examined in salmonids. For example, duplicate genes coding for IGF and MYF share 96-97\% identity [31]. The low similarity between the rainbow trout Clock 1 duplicates was due to a large insert located in intron 15/16 which had the highest BLASTN hit to intronic regions of Salmo salar HoxC cluster (EU025714) with 91\% identity (Figure 1). The region of similarity within the Salmo salar HoxC cluster was between Hox6Caa and Hox8Caa genes, which is where Hox7Caa was lost and replaced with a transposon [32]. The next highest hit to intron $15 / 16$ was to the 3' end of Salmo salar Ras-related putative protein rab-31 (BT058970) with $89 \%$ identity. Coincidentally, these regions of rab-31 and HoxC share similarity to a Tc1like DNA transposon DTSsa5 (EF685958) (89\%) (Additional File 1). The transposon-like sequence found in OmyClock1a does not contain the inverted tandem 


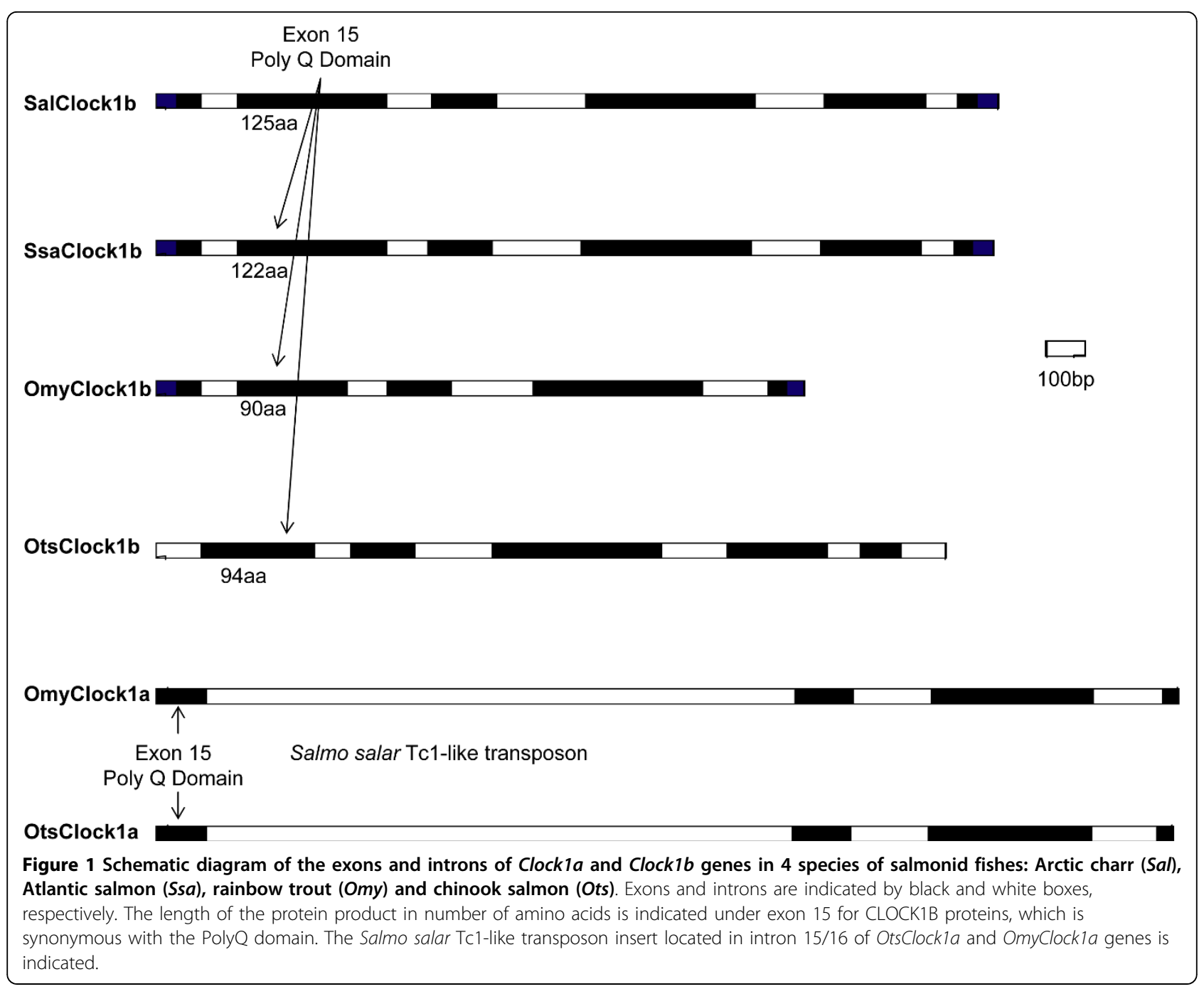

repeats (ITRs) which is essential for recognition by the transposase protein for excision to occur. If excision does not occur, the transposable element may become a permanent element that is inactive. When O'Malley and Banks [27] compared the Chinook salmon Clock1 duplicates, Otsclock1a and Otsclock1b; they reported that intron 15/16 contained a transferrin insert; however this study was published prior to the annotation of the Tc1 transposons in Salmo salar by de Boer et al. [33].

A single NPAS2-like sequence from rainbow trout (OmyNPAS2-like) showed similarity to the NPAS2 genes in stickleback and zebrafish. OmyNPAS2-like spanned exons 10 (76\% identity) and 11 (84\% identity) of the stickleback NPAS2 gene. In zebrafish, the OmyNPAS2like sequence was similar to exons 11 (81\% identity) and 12 (86\% identity). Unfortunately, this sequence was not included in the phylogenetic analysis (Figure 2) because it covered a portion of NPAS2 that was not homologous to the partial salmonid Clock1 genes. Mapping results, however, confirm that these sequences are not Clock1 orthologs (discussed later).

Phylogenetic analysis revealed that the salmonid Clock1a and Clock1b duplicates were most similar to DreClock1 with 88\% (Neighbour Joining: NJ) and 97\% (Maximum Parsimony: MP) bootstrap confidence. The orthologs OmyClock1b, SsaClock1b, SalClock1b, and Otsclock1b clustered together and orthologs OmyClock $1 a$ and Otsclock $1 a$ clustered together in both $\mathrm{NJ}$ and MP trees (Figure 2A and 2B). Thus, the orthologs within the salmonids were more similar than paralogs (e.g. OmyClock1a clustered with Otsclock1a, not OmyClock1b).

Protein alignments of the salmonid CLOCK1 sequences revealed that a polyglutamine motif region (PolyQ) in exon 15 was present in all the orthologs and that this region varied in length between duplicates and across the species (Figure 3). SALCLOCK1B and SSACLOCK1B contained the highest number of glutamine 


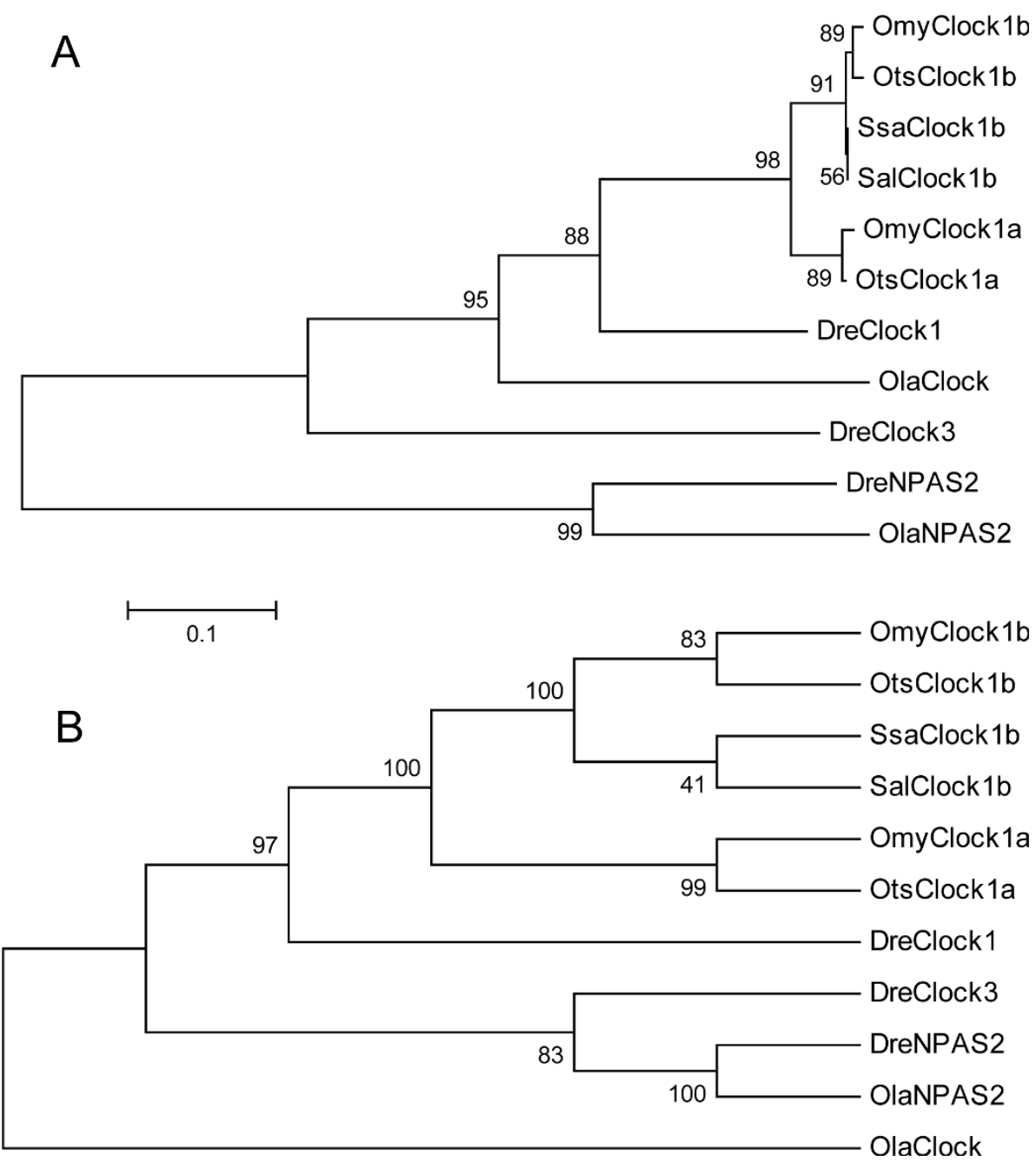

Figure 2 Phylogenetic relationship of Clock nucleotide sequences obtained from Arctic charr (Sal), Atlantic salmon (Ssa), medaka (Ola), rainbow trout (Omy), and zebrafish (Dre) coding regions. A) Neighbour-Joining. B) Maximum Parsimony. The tree was rooted to the Olaclock sequence. Values indicated at the nodes are the percent bootstrap values of 1000 replicates.

residues with a total of 63 in this region. OMYCLOCK1A contained 18 glutamine residues, whereas OMYCLOCK1B contained 36 glutamine residues. Similar to what was found for rainbow trout, Chinook salmon OTSCLOCK1A and OTSCLOCK1B contained 20 and 41 glutamine residues, respectively [27]. Other taxa show differences in the CLOCK PolyQ regions between species and even within a species. For example, this region varies in Drosophila species with glutamine counts ranging from 25 to 33 residues [34] and in avian species, like blue tits (Cyanistes caeruleus) and bluethroats (Luscinia svecica), where glutamine counts vary from 9 to 17 and 10 to 16, respectively [35].

Some species exhibit variable PolyQ tract lengths according to latitudinal gradients. For example, within species length variants were observed in blue tit and Chinook salmon [35,36]. Most importantly, these PolyQ length and latitudinal gradients appear to correlate with breeding/spawning times. At higher latitudes, mean PolyQ lengths were longer compared to lower latitudes $[35,36]$. Differences in PolyQ lengths also occurred in Chinook salmon that spawn at temporally distinct times of year in the same river [9]. Interestingly, no variation was found in the PolyQ region of OTSCLOCK1A [36]. In this current study, the presence of variable PolyQ regions in CLOCK1B across the salmonids suggests that this region may be a result of local adaptation to latitude affected ecological factors like photoperiod.

The presence of variable PolyQ regions in CLOCK1B across the salmonids suggests that this region may be important in altering circadian phenotype. PolyQ lengths have been associated to fitness parameters in other species. In a single blue tit population, Liedvogel et al. [37] found evidence that short CLOCK PolyQ 


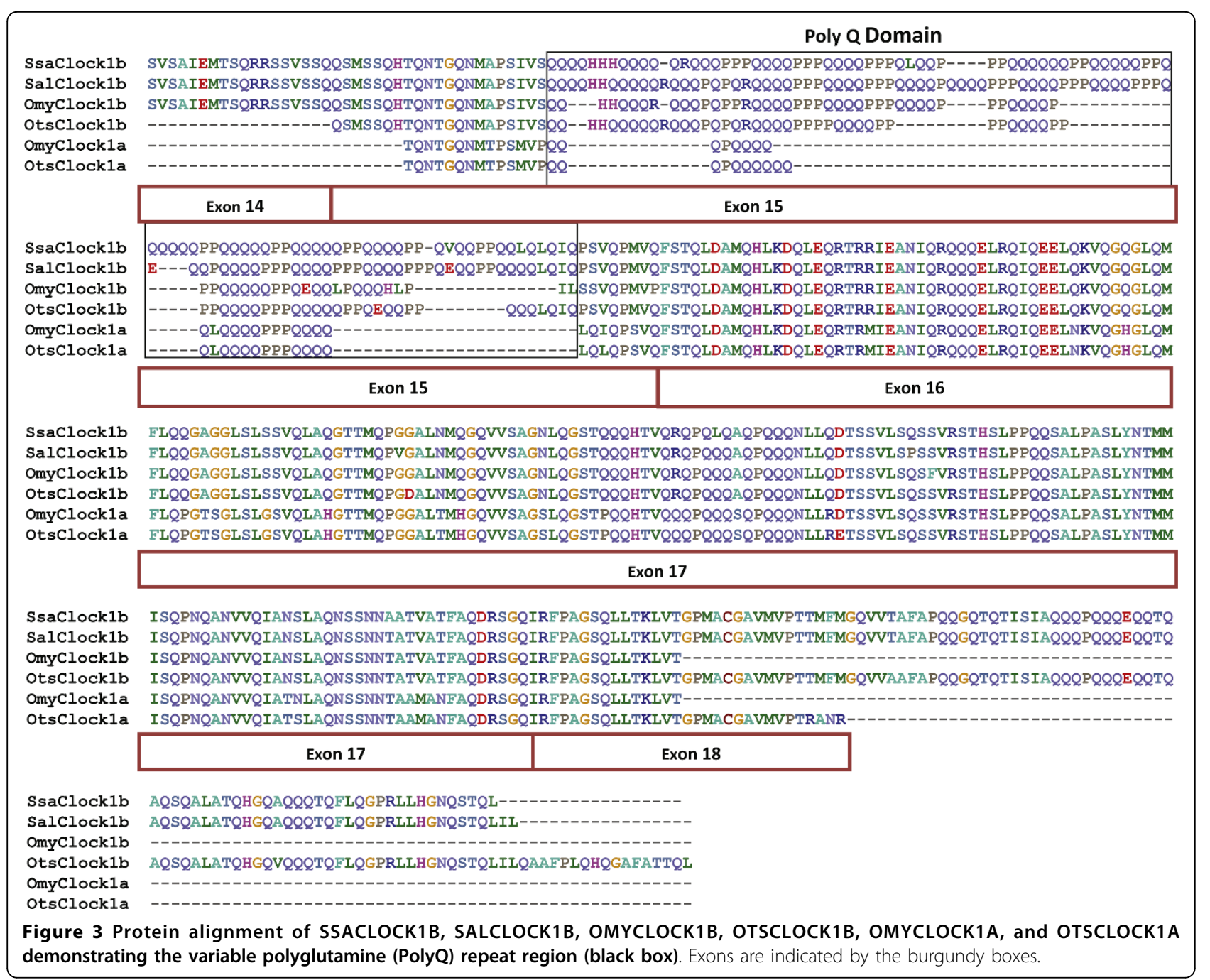

regions were correlated with earlier breeding times for females and shorter incubation periods for both males and females. In terms of fitness, females that had shorter PolyQ regions had a higher number of fledged offspring [37]. Thus, Chinook salmon populations inhabiting more northern latitudes may delay reproductive timing in relation to seasonal photoperiodicity in order to enter more favourable stream environmental conditions for spawning. However, direct comparisons of spawn timing events in female salmonids with different PolyQ tracts still need to be examined to test this hypothesis.

Acute effects of PolyQ and 3' Q-rich modulation on circadian rhythms have also been observed. Deletion of 51 amino acids in the 3' Q-rich region in mutant mice has been associated with lengthening the circadian period up to 4 hours in homozygous mice and eventual loss of rhythmicity over a few weeks in darkness [38-40]. Thus, PolyQ and 3' Q-rich variation appear to be important component of transcription activation
[41-43]. Since the PolyQ domain is involved in transactivation, the domain size is thought to directly affect the transcription of the target genes and thus phenotype [42].

\section{Mapping of Clock and amh Homologies and homeologies}

In rainbow trout, Omyclock1a mapped to the central region of linkage group RT-8 while OmyClock $1 b$ mapped to the short arm of (i.e., RT-24p) (Figure 4). amh mapped to linkage group RT-8 supporting previous findings [28], while its putative paralogous copy was localized to linkage group AC-13 in Arctic charr, which is homologous to RT-24p arm in rainbow trout (Figures 5 \&6). The mapping of Clock1 duplicates in rainbow trout and putative amh paralog assignments provides further evidence for homeologous affinities of RT-8 and RT-24 [25,44]. Additional duplicated genes have been mapped to these linkage groups including ornithine 


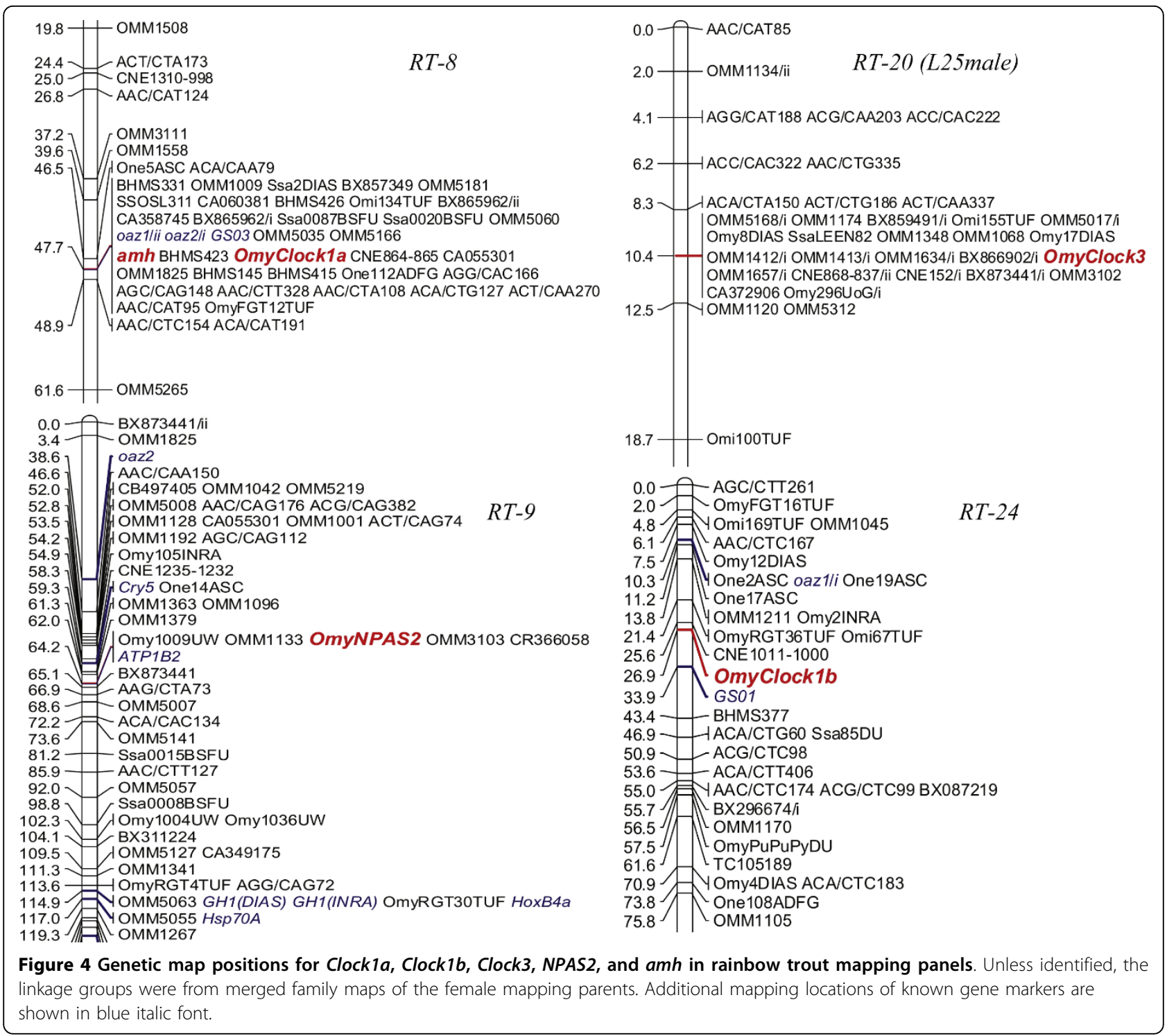

decarboxylase antizymes (oaz1/i/ii) [45] and glutamine synthetases (GS01/GS03) [46] (Figure 4). Although RT24 and RT-8 are the fourth and fifth largest chromosomes in rainbow trout, respectively, the homeologous affinities of these linkage groups are largely unknown [47]. The long arm of RT-24 shows homeologous affinities to the long arm of RT-23 based upon a single duplicated SSR marker assignment (Omy27INRA) [48] as well as a duplicated conserved non-coding element (CNE1056-1058) [26].

The mapping of the OmyNPAS2 gene to the centromeric region of RT-9 (i.e., RT-9p arm) also supports some intriguing evolutionary affinities between the RT$8 / 9 / 24$ chromosomal regions in rainbow trout (Figure 4). Centromeric regions of RT-24 and RT-9 share a degree of putative homeology based upon the syntenic mapping of a pair of duplicated markers (Omy1231INRA and Omy1287INRA) [49]. Similarly, homeology between the short arms of RT-8 and RT-9 also exists based upon the mapping of the duplicated marker OMM1825 [49], a duplicated CNE (CNE12321235) [26], and duplicated copies of the oaz2 genes [45]. However, the homeologous segments between RT-8/9 appear to be more telomeric in location on the RT-9p arm compared to those between RT-9/24.

A single copy of the OmyClock3/NPAS2-like gene was mapped to the central cluster of markers on the RT-20 linkage group in a male rainbow trout (Figure 4). RT-20 shares homology with both arms of linkage group AS-28 and given that AS-19/28 are homeologous, this region may also possess homology to linkage group arm AS19q [25]. For the RT-20 linkage group, homeologies are 


\begin{tabular}{|c|c|c|c|c|}
\hline $\left.\begin{array}{l}0.0 \\
13.0 \\
15.1 \\
15.2 \\
17.3 \\
19.5 \\
20.6 \\
21.7 \\
22.8 \\
23.8 \\
27.9 \\
29.2 \\
\\
30.3\end{array}\right]$ & $\begin{array}{l}\text { Ssa16NUIG } \\
\text { Ssa0020BSFU AS-2 } \\
\text { BHMS389 } \\
\text { Ssa1306BSFU } \\
\text { SSOSL311 Ssa0198ECIG Ssa1248BSFU } \\
\text { Ssa0072ECIG Ssa1062BSFU } \\
\text { StrA3/2 } \\
\text { Ssa0582BSFU } \\
\text { Ssa0891BSFU } \\
\text { CA358745 CL24648 CA060381 } \\
\text { ACACTG166 } \\
\text { OMM1009 BHMS417 SsaClock1a } \\
\text { SSOSL417 Ssa0101SSFU AGG/CTG94 } \\
\text { Ssa1386BSFU Ssa0193ECIG } \\
\text { Ssa1007BSFU AGG/CTG110 ACT/CTG303 } \\
\text { Ssa0716BSFU Ssa1378BSFU Ssa0597BSFU } \\
\text { Ssa0087BSFU } \\
\text { Ssa-A13 Ogo8UW Ssa0141BSFU } \\
\text { Ssa0003BSFU ACT/CTC252 } \\
\text { |BHMS212 Ssa1425BSFU Ssa0751BSFU } \\
\text { OMM1039 Ssa0844BSFU Ssa0623BSFU } \\
\text { Ssa1169BSFU Ssa10061BSFU Ssa1086BSFU } \\
\text { ISsa0824BSFU Oke4 } \\
\text { Ssa0859BSFU } \\
\text { Ssa0673BSFU } \\
\text { BHMS360 Ssa0095BSFU } \\
\text { S Ssa0614BSFU Ssa0623BSFU } \\
\text { BHMS201 Ssa1092BSFU } \\
\text { Bsa0968BSFU } \\
\text { BHMS278 BHMS159 Ssa0026BSFU } \\
\text { ACC/CTC232 Ssa0813BSFU Ssa0051ECIG } \\
\text { Ssa0458BSFU Omi85TUF } \\
\text { ACC/CAA136 OmyFGF6 } \\
\text { Omi41TUF } \\
\text { BHMS292 Ssa0349BSFU } \\
\text { BHX83380 Ssa0078ECIG Ssa10047BSFU } \\
\text { BL13269 OMM1228 } \\
\text { Ssa0031BSFU } \\
\text { SS12/ii }\end{array}$ & $\left.\begin{array}{l}0.0 \\
6.5 \\
19.6 \\
21.7 \\
30.4 \\
56.5 \\
58.7 \\
61.9 \\
63.0 \\
64.1 \\
67.3 \\
68.4 \\
69.5 \\
72.8 \\
73.9 \\
75.0 \\
77.2 \\
78.2 \\
80.4 \\
81.4 \\
82.5 \\
84.7 \\
86.9 \\
89.0 \\
89.3 \\
90.1\end{array}\right]$ 年 & $\begin{array}{c}6.4- \\
8.1 \\
9.7 \\
12.4 \\
15.2- \\
17.3- \\
22.5- \\
26.0- \\
30.0-\end{array}$ & $\begin{array}{l}\text { OmyFGT16TUF BHMS420 } \\
\text { Ssa0082ECIG CB514761 } \\
\text { SSsp1605 Ssa25EVMS } \\
\text { Ssa0357BSFU Ssa0150SSFU } \\
\text { Ssa0080ECIG Ssa0711BSFU } \\
\text { Ssa0361BSFU Ssa1348BSFU } \\
\text { BASS2161d.SPB2_A12 Ssa0960BSFU } \\
\text { AAC/CAT231 } \\
\text { Ssa1188BSFU } \\
\text { - Ssa0406BSFU SsaClock1b } \\
\text {-I Ssa0426BSFU Ssa0431BSFU } \\
\text {-I Ssa0328BSFU Ssa0631BSFU } \\
\text { - Ssa0052ECIG } \\
\text { - BHMS377 Ssa1128BSFU } \\
\text { - Ssa0665BSFU }\end{array}$ \\
\hline
\end{tabular}

only characterized extensively for the $14 \mathrm{p} / 20 \mathrm{q}$ arm duplications, although a pair of duplicated markers also indicates that RT-14q may share a degree of homeology to RT-25q. There is also evidence that a small region of homeology may exist around the centromeric regions of both RT-20 and RT-9 based upon the presence of up to 3 duplicated markers that have been genotyped in different mapping panels $[25,50]$.

In Atlantic salmon, SsaClock1a and SsaClock1b mapped to the AS-2qa region of AS-2 [51] and AS-18, respectively (Figure 5). AS-18 represents an acrocentric chromosome in Atlantic salmon, which shares homology to only a single rainbow trout linkage group arm (i.e., RT-24p), and thus is not designated with respect to arm regions in the species. AS-2, a fused acrocentric chromosome in Atlantic salmon, shares homology to two rainbow trout linkage group arms (i.e., RT-8q in the AS-2qa region proximal to the centromere, and RT-27q in the more distal AS-2qb region [51]). SsaNPAS2 mapped to AS-5, and more specifically to the AS-5qb region of the linkage group. AS-5 is also a fused acrocentric chromosome in Atlantic salmon, with the AS$5 q$ a region homologous to $\mathrm{RT}-22 \mathrm{q}$, and the AS-5qb region homologous to RT-9p [51]. Interestingly, while the Clock1 duplicates in rainbow trout, along with $N P A S 2$ gene copy appear to fall into regions that may possess a degree of ancestral homeology (based upon the syntenic mapping of additional duplicated genetic markers), the observed mapping locations for these genes in Atlantic salmon is not supported by any additional duplicated marker information (however, see below for discussion on ancestral homologies).

In Arctic charr, SalClock1a and SalClock1b were localized to linkage groups AC-16 and AC-13, respectively, and SalClock3/NPAS2-like duplicates mapped to AC-20 and AC-43 (Figure 6). Similar to Atlantic salmon, there are no known homeologies recognized between AC-13/ 16 , or $\mathrm{AC}-20 / 43$. Current mapping data indicate that segments of AC-13 may share homeology to AC-14 (1 marker) and AC-34 (9 markers), while a single duplicated marker supports potential homeology between AC-16 and AC-27 [[52]; unpublished data]. AC-43 does not share any duplicated markers with other linkage groups in the Arctic charr genome, while AC-20, appears to be a fused metacentric chromosome possessing chromosome arms that are homeologs to one another [52]. These linkage group arms are homologous to the RT-2q and RT-9q linkage group arms in the rainbow trout genome [25].

Homologous linkage group alignments between the species indicate that $\mathrm{AC}-16$ is homologous to the RT-8 linkage group. Given the tight clustering of markers on RT-8 due to the lack of recombination in the female mapping parents used to construct the rainbow trout 


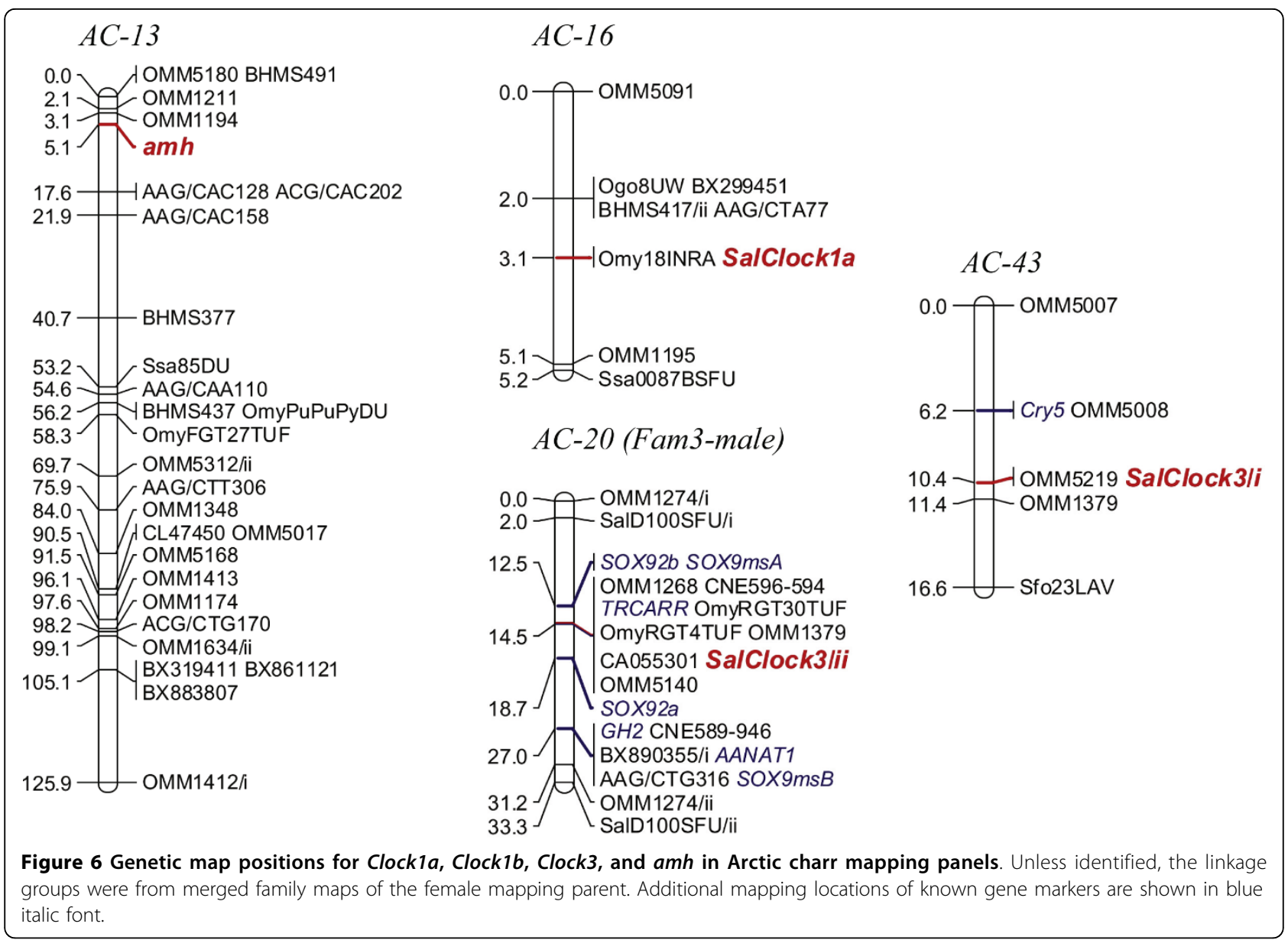

genetic linkage maps [53], the actual RT-8 arm assignments to AC-16 are difficult to determine. However, within the cluster of markers on AC-16, two markers (Ogo8UW and BX299451) are evident, and these are located quite distally along the RT-8q chromosome arm (see Figure 4). This would suggest that this rainbow trout chromosome arm (i.e., RT-8q) shares homology to AC-16, and this interpretation is also compatible to the assignment of shared homology to the AS-2qa linkage group arm.

The assessment of homology for the SalClock1b mapping location on $\mathrm{AC}-13$ is even more difficult given the fact that the linkage assignment is only based upon male segregation data (See Figure 6). AC-13 appears to be a metacentric chromosome in Arctic charr with the AC-13p arm homologous to the RT-24p arm, and the AC-13q arm homologous with RT-14p or RT-20q linkage group arms [25].

Since the mapping location of amh in Arctic charr is clearly homologous to the RT-24p arm (Figures 4 and 6) in rainbow trout, and given the syntenic clustering of Clock1 and amh on RT-8, it may be inferred that the homology of the SalClock1b copy is to the RT-24p arm.
The differential localization of amh copies to RT-8 and AC-13 indicates that duplicates of this gene may still exist in both rainbow trout and Arctic charr on the RT24p, and AC-16 linkage groups, respectively. Alternatively, following the $4 \mathrm{R}$ duplication of these genes, one of the two duplicated copies may have been differentially silenced within the respective alternate homeologous linkage group arms of either species.

Mapping of the duplicated SalClock3/NPAS2-like copies to AC-20/43 is particularly intriguing, given the fact that these linkage group regions have distinct homologies to separate linkage group arms in rainbow trout and Atlantic salmon. AC-43 is homologous to the RT-9p arm (Figures 4 and 6), and the AS-5qb (Figures 5 and 6) linkage group arms. Both of these linkage group regions possess a copy of the NPAS2 gene, as previously mentioned. Given that a more precise localization of OmyClock3/NPAS2-like is not possible based upon the male genotyping data obtained in this study, it is reasonable to assume that this gene maps to the RT-9p arm as well, given that AC-43 and RT-9p share homology. If, however, we consider that the duplicated copy of the SalClock3/NPAS2-like gene maps to AC-20 (which share 
homology with only the RT-9q arm) then two copies of these genes may in fact exist on the RT-9 linkage group in rainbow trout (see below).

\section{Affinities to ancestral Actinopterygian linkage groups}

Comparative synteny analyses between the salmonids and model fish species, such as zebrafish, stickleback and medaka, can be used to determine the origin of ancient genomic regions in fish species. These comparative genomic studies suggest that modern day ray-finned fishes descended from an ancestral vertebrate lineage that had 12-13 linkage groups (A-M) [54-56]. Using information on the salmonid-specific linkage group arm homologies to the ancient ancestral linkage group arm origins [25], the duplicated Clock1 and amh copies in the salmonid species have likely arisen from the $M$ ancestral lineage. Linkage group arms RT-8q; RT-24p; AS-2qa and AS-18 all share homology to the M ancestral lineage.

BLASTN alignments of the OmyClock $1 b$ gene to the medaka genome also indicate that there may be an unannotated Clock gene copy within Ol-4 at $1.755 \mathrm{Mb}$. The Fgenesh- $\mathrm{M}$ analysis [57] suggests that this assignment may be a pseudogene signature given that the alignment blocks do not overlap any of the predicted exons within the region. Regardless, this region would be considered most similar to OmyClock1b, making Ol-4 the most informative syntenic block for ancestral linkage group assignments. Using this information, the association of Ol-4 to ancestral lineage $\mathrm{M}$ is compatible with the major ancestral assignments in the salmonids [25]. Ol-4 genes also share a synteny block with the Clock copy on Dr-20 (spanning from the Clock gene at 21.381 Mb-23.259 Mb, and homologous to the region from $0-1.733 \mathrm{Mb}$ in medaka), suggesting homology to the $M$ lineage. The Clock copy in sticklebacks ( $0.489 \mathrm{Mb}$ on Ga-IX), however, shares greatest homology to a region on Dr-1 from 13.624-26.952 Mb, and to Ol-1 within the region from 14.996-15.785 Mb on this medaka chromosome. Clock3 in zebrafish is localized to $\mathrm{Dr}-1$ at $18.849 \mathrm{Mb}$, while Clock3 in medaka is localized to Ol-1 at $14.996 \mathrm{Mb}$. Kasahara et al. [55] indicate that $\mathrm{Ol}-1$ is derived from a mosaic mixture of genes that derive from the $\mathrm{E}$ and $\mathrm{F}$ ancestral lineages in fish indicating that Clock3 gene copies likely have a different teleost-specific ancestral chromosomal origin compared to the Clock1 copies. This would then suggest that the region of Ga-IX possessing Clock derives from a different origin than the Clock copies on Dr-20 and Ol-4, and is in fact more similar to Clock3 copies in zebrafish and medaka.

The single copy of OmyClock3 mapped to RT-20 in rainbow trout is compatible with a hypothesis that this Clock3 gene arose from the $\mathrm{F}$ ancestral lineage as genetic markers possessing homology to both Ol-1/-18 are located on the RT-20q linkage group arms [25].
However, the copy of SalClock3/NPAS2-like that is located on AC-20, would suggest that homology to the RT-9 linkage group may exist for two Clock gene copies. AC-43 is homologous to RT-9p (SalClock3/ NPAS2-like/i location) while AC-20 (SalClock3/NPAS2like/ii) is homologous RT-9q. The copy on AC-43 is likely NPAS2, as this matches the location of this gene in rainbow trout. The copy on AC-20, may, however, be representative of Clock3. While it is true that there is extensive homology to the $\mathrm{E}$ ancestral grouping on the RT-9q linkage group arm, there is also a small region of homeology to the $\mathrm{G}$ lineage around the centromere representative of duplicated markers between RT-9/20 (as previously mentioned).

In stickleback, the most likely OmyNPAS2 BLASTN homology was to a pair of partial exons at $17.213 \mathrm{Mb}$ on Ga-VII while the NPAS2 gene has been assigned to chromosome Ga-VII at 17.209 Mb. Interestingly, both Ga-VII and Ga-IX appear to share extensive homeology to one another throughout the proximal regions of both linkage groups. The region designated as possessing Clock on Ga-IX is not homologous to the ancestral $\mathrm{M}$ lineage regions containing the salmonid Clock1a and Clock1b copies. These regions are, however, homologous with the chromosome segments of Ol-18 and Dr-7 within Ga-VII, and with Ol-1 and Dr-1 within Ga-IX, which clearly indicates their affinities to the $F$ ancestral lineage of teleost fishes $[25,55,56]$. This would indicate that the "Clock-like" copy designated as NPAS2 on GaVII within the ENSEMBL 56 release is, in fact, a duplicate copy of Clock3, with the homeolog of this gene still evident on Ga-IX.

BLASTN homologies of OmyNPAS2 within the medaka genome are to chromosome $\mathrm{Ol}-14$ at 17.143 $\mathrm{Mb}$, and to Dr-5 at 20.844 Mb in zebrafish and both of these regions are descended from the GH ancestral lineage [25]. The Ol-14 region possessing NPAS2 has extensive homology to $\mathrm{Dr}-21$, while the $\mathrm{Dr}-5$ region containing NPAS2 has extensive homology to Ol-10 and -14 . To highlight the similarity in these gene copies, the first exon region (1-155 bp) of the OmyNPAS2 gene also has extensive homology to the zebrafish Clock3 gene on Dr-1 (85.1\% identity within $148 \mathrm{bp}$ ), and Clock1 copy on Dr20 (82.1\% identity within $162 \mathrm{bp}$ ). In addition, the OmyNPAS2 sequence has a high degree of homology to an unannotated sequence block (85.8\% identity for $148 \mathrm{bp}$ ) within $\mathrm{Dr}-15$ between the genes LOC568103 and kitb. Both kita and kitb genes are companion syntenic genes to the Clock genes among vertebrates. The copy on Dr-15 may be a functional NPAS2 copy based upon the Fgenesh-M analysis [57] that is currently unannotated, and given the fact that major chromosomal segments of Dr-10, $-14,-15$, and -21 are derived from the GH lineage, it would suggest that the 
BLASTN alignment of the OmyNPAS2 gene on Dr-15 represents a 3R homeolog of NPAS2.

In summary, it can be stated that the Clock1 homeologs in rainbow trout and Atlantic salmon are all derived from ancestral linkage group $\mathrm{M}$. The genomic regions surrounding NPAS2 are derived from ancestral linkage group $\mathrm{GH}$, and regions surrounding Clock3 are derived from teleost ancestral linkage group F. At present, it is not possible to clearly assign the OmyClock3/ NPAS2-like copy on RT-20 to an origin either from the $\mathrm{GH}$ or $\mathrm{F}$ lineages because homeologies exist both between RT-9/20 (possible GH lineage) and RT-14/20 (possible F lineage).

By tracing ancient linkage groups $\mathrm{GH}$ and $\mathrm{F}$ even further back in vertebrate evolution it is possible to ascribe the origins of the proto-Actinopterygian linkage groups to 10-13 putative proto-vertebrate linkage groups (designated A' - J' or possibly A' - M') [56]. These linkage groups underwent two rounds of whole genome duplications and extensive fusions prior to a further $3 R$ duplication in the teleost fishes. When these lineages are configured within the 12-13 proto-Actinopterygian linkage groups it is intriguing to note that almost all of ancestral linkage groups $\mathrm{G}$ and $\mathrm{F}$ are derived from C' lineage blocks (i.e., $\mathrm{C} 1$ and $\mathrm{C} 2$ ) [56]. Thus, the extensive homology observed between the NPAS2 and Clock3 gene copies across the various teleost species compared may not be that surprising given that they are likely derived from multiple gene duplications from the same ancestral gene. Additionally, two lineages of NPAS2 genes exist in vertebrates (a teleost-specific form and Sarcopterygian form) with the teleost-specific form more closely related to Clock 3 and Clock 1 vertebrate genes [see data for family TF324568 in: http://www.treefam.org]. This suggests differential silencing and retention of paralogous copies of the NPAS2 gene following either the $1 R$ or $2 R$ duplication events in the vertebrate lineages. The extensive overlap of inferred homeologies seen within rainbow trout in the current study for the NPAS 2 and Clock 3 copies is also consistent with these observed phylogenetic affinities.

\section{Co-localization of Clock and amh with life-history and growth QTL}

In this current study, OmyClock1a and amh were localized in the central cluster of markers with zero recombination on RT-8 including OmyFGT12TUF, OMM1009, and SSOSL311, while OmyClock1b and $a m h$ (Arctic charr maps) were mapped in close proximity to BHMS377 and OmyRGT36TUF markers (Figure 4), which are homologous to RT-24 in rainbow trout. These markers fall within genomic regions that contain QTL for important life-history traits in salmonids such as spawning time, early maturation, and development rate $[8,44,58-64]$ suggesting that Clock1 homeologs and putative amh duplicates may be candidate genes affecting these traits.

The strong spawning time QTL located on RT-8 in a backcross family (Lot44) [58] accounted for up to 50$60 \%$ of the trait variation $[8,58,60]$. Due to the lack of recombination that has been detected in both sexes within this chromosomal region [47], it has been difficult to assess the chromosomal arm location for these QTL effects. However, using the comparative synteny mapping approaches outlined above, it appears that the most likely locations for these genes fall within the RT$8 \mathrm{q}$ arm (i.e., derived from the $\mathrm{M}$ ancestral lineage). Counter to this observation, the strongest early maturation QTL region on RT-8 was localized to the marker OMM1304 on the RT-8p arm [44], indicating an origin to the I ancestral lineage of teleost fishes [25]. However, relatively strong QTL for this trait were also detected for several makers falling within the central cluster of markers which could, therefore, indicate interaction effects among these regions.

Development rate QTLs have also been localized to the central region of RT-8. For example, Sundin et al. [61] suggested that a development rate QTL was located on this linkage group (associated with markers OmyFGT12TUF, OMM1009). A subsequent study, using doubled haploid lines of rainbow trout confirmed that a major developmental rate QTL was localized in the central clusters of RT-8. This QTL explained a large proportion of the phenotypic variation (23.2\%) associated with the trait [64].

OmyClock $1 b$ also mapped to a region of the rainbow trout genome (i.e., RT-24) with strong influences on variation in life-history traits. Regions on RT-24p (BHMS377 and OmyRGT36TUF) occupied by Clock1b explained up to $20 \%$ of variation in the spawning time of females $[8,60]$. Maturation timing QTL have also been localized to RT-24 [44,59] but given the fact that these QTL were localized in male parents, the determination of the chromosome arm affinities was not possible. Similarly, a small effect development rate QTL (one of four along with RT-9, -10, -14) was localized to RT24 , which explained approximately $1.26 \%$ of phenotypic variation [64].

Other locations of Clock-like genes are also associated with life-history QTL in rainbow trout. The NPAS2 copy mapped on RT-9 may correspond to one of the developmental rate QTL identified in the Nichols et al. [64] study. Additionally, a strong QTL for the timing of smoltification in rainbow trout has been localized to RT-20 [65] which may be related to Clock3 functional differences.

In Arctic charr, SalClock1a was localized to AC-16, and SalClock1b and amh were localized to AC-13 both of which contain suggestive female maturation time 
QTL. On AC-16, SalClock1a is closely linked (0 cM recombination) to Omy18INRA and BHMS417, markers that suggestively influence age at sexual maturation in females [63]. Likewise, SalClock1b and $a m h$ were linked to OMM1211 on AC-13 in the Arctic charr maps at 0 $\mathrm{cM}$ and $3 \mathrm{cM}$ recombination, respectively. This linkage group contains a suggestive age at maturation QTL centered on OMM1211. Both QTL on AC-16 and AC13 explained approximately $7 \%$ of the phenotypic variation [63].

Studies investigating genetic associations with life-history variation in Atlantic salmon have not been as extensive as those with rainbow trout or Arctic charr. Fotherby [62] identified 11 putative QTL for early maturation in female Atlantic salmon (at 3 years), but only two of these (i.e., AS-17 and AS-28) overlapped with a region homologous to a rainbow trout linkage group containing a possible Clock-related gene effect. The region identified on AS-17 (marked by One114ADFG) is homologous to the RT-8p arm. One114ADFG is in fact only $4 \mathrm{cM}$ distal to OMM1304 in female rainbow trout genetic maps, where the strong maturation timing QTL was detected in the Haidle et al. [44] study. A marker located distally on AS-28, BX873441, has homology to the distal region of $\mathrm{RT}-9 \mathrm{p}$, while a proximal marker, CL47450, shows homology to rainbow trout duplicated homeologs RT-14/20. As mentioned above, RT-9p possesses an NPAS2 copy, while Clock3 maps to RT-20, and may possess a duplicate within either the RT-9/20 or RT$14 / 20$ homeology groups.

Rainbow trout is perhaps the most characterized salmonid species with respect to growth QTL. QTL on RT-8, RT-9 and RT-24, which also coincide with the location of Clock-related genes, have strong influences on body weight (BW) [66]. While significant BW QTL were also identified on RT-14 and RT-20, these linkage groups were not observed to be significant across all the parents tested, and thus were not considered to house major BW species-specific QTL regions. Future studies across multiple families in different strains may lead to a different conclusion. The association among variation in multiple life-history and phenotypic traits with Clockrelated chromosomal regions suggests the existence of conserved blocks of genes regulating single or multiple traits (discussed in the next section) [44,61].

\section{Synteny analyses: conserved blocks of reproductive and cell cycling genes}

Synteny analysis across teleost species revealed a conserved block of genes surrounding the $a m h$ gene which suggests the presence of a functional cluster [67]. Comparative analysis of amh containing regions on medaka chromosome 4, tetraodon chromosome 1, and zebrafish chromosome 22 revealed conserved synteny of 12 genes, including $l h x 7, h s d 11 b, \operatorname{map} 2 k 2$, LINGO3, oaz1, DOT1L, $E L L, v t g, d d x 59, n r 5 a 2$, kif14, and $\operatorname{lh} x 9$ involved with sexual maturation and cell cycling. With the exception of DOT1L, all these genes appear to exhibit circadian oscillations in one or more mammalian tissues, suggesting either direct, or CCG-mediated regulation via Clock gene expression [68] (Additional File 2). When the teleost genomic regions surrounding amh were compared to the human chromosome 19 , there was conserved synteny of DOT1L, oaz1, LINGO3, map $2 k 2$, and $h s d 11 b$ genes. Clock was found on the same chromosomes as amh within medaka and tetraodon, and Clock was tightly linked to kita across all the species investigated (Additional File 2).

Genes regulating reproduction include $\ln x 9, \ln x 7$, $n r 5 a 2, h s d 11 b 3$, and kit. For instance, members of the LIM homeobox ( $\operatorname{lh} x 9$ and $\operatorname{lh} x 7$ ) are found adjacent to $a m h$ in medaka, tetraodon, and zebrafish. $L h x 9$ is essential for gonadal development in mice as $L h x 9$-deficient mice developed without gonadal tissues [69,70]. Lhx7 (or $\operatorname{lh} x 8$ ) code for a transcription factor that plays a critical role in folliculogenesis. An $L h x 7$ deficiency results in altered expression of oocyte-specific genes in the ovary, and is therefore thought to be critical in follicle formation and differentiation and maintenance of oocytes [71]. Likewise, LRH-1 (nr5a2) is found upstream to $a m h$ in the teleost species. This gene is an orphan nuclear receptor, is a critical regulator of multiple mechanisms essential for maturation of ovarian follicles and for ovulation [72]. LRH-1 mutants resulted in increased estradiol synthesis and downregulation of genes (Scarb1, Star, Cyp11a1) critical for luteinization [72]. Because of these effects, it is thought that $L R H-1$ is primarily important for female sexual function relative to $S F-1$ (nr5a1), which is involved in male sexual development [73].

As well, the Hsd11b3 gene is found adjacent to $a m h$ in medaka, tetraodon, zebrafish and fugu (Additional File 2). HSD11B3 (11 $\beta$-hydroxysteroid dehydrogenase type 3 ) is a steroidogenic enzyme that is involved in the production of 11-ketotestosterone [74] the main androgen sex steroid which effects spermatogenesis and secondary sexual characteristics in male teleosts [75,76]. Mutations within the $H s d 11 b 3$ gene have also been linked to pseudohermaphrodism in human males due to altered sex steroid ratios [77]. In both sexes, HSD11B3 is also important for the conversion of glucocorticoids into inert forms [78]. Corticosteroids have been linked to suppression of steroidogenesis in mammals, therefore HSD11B enzymes are thought to be important in protecting the developing gametes from high cortisol levels [79-81].

In addition to its functions related to melanogenesis and haemopoiesis the $c$-Kit gene is also important in 
regulating gametogenesis in vertebrates [82], and has also been implicated in lipid metabolism as mice deficient for this gene exhibit steatosis of the liver during development [83]. Kit is found adjacent to Clock and amh in medaka, and tetraodon while in zebrafish, fugu, human, and mouse Kit and Clock are adjacent on different chromosomes than amh. Kit tyrosine-kinase receptor and its ligand $(\mathrm{KL})$ are essential for spermatogenesis as they upregulate genes that promote mitosis, and meiosis entry of spermatogonia [84]. Also, Kit is involved in oogenesis and follliculogenesis in female mammals (reviewed in [85]). Direct Clock-related regulation of this gene may also occur through retinoic acid stimulation of Activator Protein 2 (AP-2) expression. AP-2 as well as bHLH binding sites are present in the $c$ Kit gene [86], and Shirai et al. [87] have shown than there is a bidirectional regulation of Clock/bmal1 regulated genes and retinoic acid levels mediated through the expression of retinoic acid orphan receptors.

Specific to the fishes, vitellogenin ( $v t g$ ) is found downstream to $a m h$ (Additional File 2). Vitellogenin is a precursor yolk protein in fish eggs, and it gene is regulated as a result of estrogen binding [88]. Estrogen levels and indeed sex steroid production in general may be directly influenced by CLOCK levels, as the functional expression for one of the key enzymes regulating their production (i.e., steroidogenic acute regulatory protein or StAR) has been shown to be altered via Clock/bmal1 expression [89]. Thus Clock expression may provide direct regulation of subsequent VTG production.

Direct regulation of AMH production via Clock gene expression is also considered possible given the fact that Steroidogenic Factor 1 (SF-1) binding sites (a downstream CCG gene) have been identified within the 5' region of the amh gene in both mammals [90] and fish [91]. SF-1 (nr5a1) is the closest nuclear orphan receptor family member to the $L R H-1$ gene (nr5a2) [92]. Given the more prominent role of LRH-1 in ovarian development, compared to SF-1 [73] it would be of interest to investigate potential cis-regulation of amh via $n r 5 a 2$ in future studies. Given the interactions that several of the 'Clock/amh-syntenic' genes exhibit in the formation and maintenance of gonadal structures in both male and female teleosts, we may consider that the genes found in this cluster represent a 'reproduction controlling block'.

Genes involved in cell cycling (kif14, map2k2, DOT1L, and $o a z 1)$ are also found in conserved synteny surrounding amh across the species investigated. For example, Kif14 is found upstream to amh in medaka, tetraodon, and zebrafish (Additional File 2). Kif14 codes for a kinesin motor protein that regulates intracellular movements. Silencing of KIF14 using strong RNA interference resulted in cytokinesis failure while weak RNA interference-mediated silencing caused apoptosis of cells during various stages of mitosis [93]. Likewise, Map2k2 is found tightly linked with $a m h$ across the vertebrate species examined. MAP2K2 is part of a signal transduction pathway (MEK/ERK/MAP kinase) that promotes cell cycling. Similarly, DOT1L is tightly linked to $a m h$ among teleosts, and this gene codes for a histone methyltransferase (H3K79) that is associated with meiotic checkpoint control, and DNA damage response in yeast $[94,95]$. DOT1L deficient mice demonstrated developmental abnormalities that ultimately lead to death [96]. oaz1, like DOT1L and map $2 k 2$, is tightly linked to $a m h$, and this gene codes for a protein that binds to and promotes degradation of ornithine decarboxylase $(O D C)$, a protein that is involved in the regulation of mitotic turnover rates by controlling polyamine levels [97-99].

Interestingly, some of the genes in this conserved cluster are involved in transcription control, cell cycling, and regulation of circadian rhythms. For example, both ELL and $d d x 59$ expression is associated with RNA metabolism and these genes are adjacent to amh (Additional File 2). DDX59 is a member of the DEAD-box proteins, which are intimately involved in RNA metabolism as they regulate translation and gene expression in organelles (reviewed in [100]). ELL functions as an RNA polymerase II elongation factor that increases the overall rate of transcription, and regulates mitotic phase transitions during the cell cycle [101]. ELL also regulates glucocorticoid steroid receptor responses, which may partially modulate CLOCK:BMAL1 heterodimer activation [102], but does not influence androgen and progesterone receptors [101].

There is evidence that gene order on chromosomes is not random in zebrafish, and in fact, co-expressed genes tend to be found in close proximity to each other [103] comprising functional clusters. Overall, the comparative genomic analysis among the teleost species shows that 'Clock-containing' chromosomal segments are highly conserved. We would therefore predict that the genes found in this syntenic cluster will also co-occur on RT-8 or its homeolog RT-24 (i.e., two of the strongest life-history QTL regions in rainbow trout). However, additional life-history QTL regions may also be partially regulated via Clock expression if they possess CCGs.

\section{Clock mediated regulation of reproductive/cell cycling genes associated with salmonid life-history QTL regions}

In mammalian systems, microarray studies of circadian gene expression indicate that most circadian regulated genes are either directly modulated via Clock or Clockinducible gene expression as the majority of genes identified as showing circadian rhythms in their expression possessed E-box, AP-2, CRE, SP1 and EGR transcription factor binding sites in their 5 ' regulatory regions [68]. 
CLOCK:BMAL1 heterodimers bind to E-box sequences in the 5' regions of genes and directly influence their expression. Such CCGs are therefore considered to be under direct circadian control. Some of these genes are implicated in reproduction and growth and have been mapped to rainbow trout life-history QTL regions, or may reside within such QTL regions based upon putative homologous synteny comparisons among teleost species [25]. For example, both Gonadotropin (GnRH) and gonadotropin receptor $(G n R H R)$ promoter regions contain several non-canonical consensus E-boxes (CANNTK) sites [104,105]. GnRH and GnRHR expression patterns were disrupted by the Clock mutation in mice $[6,105]$. As a result, Clock mutant mice exhibited prolonged estrous cycles and were subfertile [6]. GnRH maps to RT-30 and RT-6 [8] and the copy on RT-30 may contribute to a strong maturation timing QTL in rainbow trout [44].

Another gene potentially coupled to QTL variation in rainbow trout is estrogen receptor beta $(E R \beta, n r 3 a 2)$, which is a member of the nuclear receptor superfamily and a key mediator of estrogen action [106,107]. ER $\beta$ shows circadian oscillations in expression and not surprisingly has an E-box element in the promoter region which allows for direct Clock gene control [108]. A copy of $E R \beta$ (esr $2 a$ ) is located less than $1 \mathrm{Mb}$ away from the Clock gene on zebrafish chromosome Dr-20, which would make this gene a contributing candidate to the DR, SPT and EM QTL that have been detected on RT24. Another gene that is related to reproduction and is under direct Clock gene control is $S t A R$, which regulates the rate-limiting step of steroidogenesis. StAR showed circadian rhythms, and contains E-box regions in promoter regions that allow CLOCK:BMAL1 to activate transcription [89]. bmal1 knock-out mice were infertile and gonadotropin levels were altered [109]. Alvarez et al. [109] found that StAR expression was not altered in Clock mutant mice; however, they did not assess the effects of the Clock homolog NPAS2 mutants. StAR maps to $45.651 \mathrm{Mb}$ on $\mathrm{Dr}-8$, and to $18.480 \mathrm{Mb}$ on medaka linkage group Ol-9 which makes this gene part of the I ancestral lineage of teleost fishes [55]. Using comparative synteny blocks to the rainbow trout genome, it is inferred that the most likely map position for this gene with either be the RT-10p or RT-19q linkage group arms [25]. EM and SPT QTL have been localized to RT-19 $[8,44]$.

Some of the cell-cycle genes (e.g. Wee1) involved in either G2-M or G1-S transitions contain E-boxes [110] indicating their status as a CCG. Wee1 is a protein kinase known to be involved in mitotic entry checkpoint in eukaryotic cells as it regulates phosphorylation status of $\mathrm{CDC} 2$ whose activity is required for a cell to enter mitosis. Besides growth, cancer is related to cell-cycling, and as such, CLOCK:BMAL1 heterodimers regulate the expression of $c-M Y C$ oncoprotein, which cooperates with $A T M$ (ataxia-telangeictasia mutated), in promoting apoptosis and suppressing tumorigenesis [111]. NPAS2: BMAL1 heterodimers coincidentally influence $c-M Y C$ expression [112]. A recent PCR array study demonstrated that NPAS2 knockdowns in vitro resulted in significant effects on genes involved in cell cycling and DNA repair, which further supports that circadian genes may play a role in tumorigenesis and cell cycling $[111,113]$. Rainbow trout linkage group regions with greatest homology to Dr-18 and Ol-6 where Wee-1 has been mapped are the homeologous pair RT-10q/18, and may be associated with a moderate DR QTL effect on RT-10 [64].

Several genes influencing reproduction and growth contain potential Clock/bmal1 regulatory sites (E-box sequences) and demonstrate circadian oscillations in certain tissues within the mouse [68]. For example, promoter regions of follicle stimulating hormone receptor $(F S H R)$, androgen receptor $(A R)$ and growth differentiation factor 9 ( $G d f 9$ ) contain E-box sequences in their promoter regions, and thus may be partially regulated in a CCG fashion $[114,115]$. As hormone receptors, both FSHR and AR expression is required to enable the signal transduction of FSH and testosterone, in order for spermatogenesis to occur [116]. GDF9 is critical for normal ovarian function as it regulates key genes (i.e. kit ligand, $\mathrm{LH}$ receptor, prostaglandins, and progesterone) involved in folliculogenesis [115]. As well, SF-1 ( $n r 5 a 1)$, an orphan nuclear receptor that regulates the expression of the steroidogenic genes and sexual differentiation (reviewed in [73]) contains E-box sequence in the promoter region [117]. Luteinizing hormone itself also appears to be under circadian control as the LH surge required in proestrous was not seen in Clock mutant mice [118]. $L H$ itself contains E-box motifs in the promoter region [119], which suggests that $\mathrm{LH}$ production is under direct CLOCK:BMAL1 control. Upstream control may also occur with vasopressin, an LH regulator, which is directly regulated by CLOCK:BMAL1 [118].

Currently mapping data is only available for $S F-1$ in zebrafish, making syntenic comparisons to the rainbow trout genome difficult. For the other 4 genes, however, it is known that $L H$ maps to RT-17 (i.e., GTH2B) [120], and it is also predicted that FSHR maps to RT-17q as this gene is located on Dr-12 at $29.005 \mathrm{Mb}$, and on Ol19 at $11.455 \mathrm{Mb}$. This region is reported to possess a strong EM QTL [44]. Interestingly, both $A R$ and $G d f 9$ may also map to a single genomic region (i.e., the homeologous pair RT-3q/25p), as AR maps to Dr-5 at 35.987 $\mathrm{Mb}$, and within $\mathrm{Ol}-10$ at $18.354 \mathrm{Mb}$, while Gdf9 maps to $\mathrm{Dr}-14$ at $23.776 \mathrm{Mb}$ and $\mathrm{Ol}-10$ at $13.566 \mathrm{Mb}$, making both these genes likely descendants from the GH 
Actinopterygian chromosome lineage [25]. Moderately strong EM and SPT QTL have been localized to RT-3 $[8,44]$.

\section{Conclusions}

Multiple Clock-family gene copies have been identified in this study (i.e., up to 5 in rainbow trout), that map to duplicated homeologous linkage group positions in the various salmonid species investigated. The NPAS2 and Clock3 genes within this family appear ancestrally more closely related, than do the Clock1 copies, and the physical linkage of the Clock1 gene duplicates to major lifehistory QTL regions in salmonid fishes, posits their functional role in regulating many of the associated lifehistory traits that have been studied in these fishes. Intriguingly, many genes important in regulating growth and life-history events are known to occur in sytenic clusters close to the Clock gene clusters. As an example, one of the most important genes regulating maturation timing in salmonids (i.e., anti-mullerian hormone), was mapped within a syntenic region of the Clock1a gene in rainbow trout. However, in Arctic charr, this gene was located within the Clock1b gene syntenic block, indicating differential silencing of the duplicated copies following the salmonid specific $4 \mathrm{R}$ gene duplication event. The functional associations of Clock gene regulation in relation to cis- and trans-effects on gene expression within these genes and additional Clock Controlled Genes within salmonids remains to be investigated.

\section{Methods \\ Mapping panels}

Six mapping panels (full-sib families) were used for mapping the Clock and amh genes. Rainbow trout panels were designated as Lot- $25(\mathrm{n}=48)$ and Lot- $44(\mathrm{n}$ = 90) [53], Arctic charr panels as AC2 $(\mathrm{n}=48)$ and AC3 $(\mathrm{n}=48)$ [52], and Atlantic salmon panels as BR5 $(\mathrm{n}=46)$ and BR6 $(\mathrm{n}=46)$ [53].

\section{Sequencing of Clock genes}

The Clock genes were amplified in five individuals from each of the rainbow trout (Lot25 and Lot44), Atlantic salmon (BR5 and BR6), and Arctic charr (AC2 and AC3) families. To amplify Clock in the salmonines, primers were designed from two Clock genomic sequences from Chinook salmon Otsclock1a (Genbank: DQ780892) and Otsclock1b (Genbank: DQ780894). Clock3 (Ensembl: ENSDARG00000003631) and NPAS2 (Ensembl: ENSDARG00000016536) sequences from zebrafish were used to search the Atlantic salmon BAC End sequences database [121] for putative Clock3 and NPAS2 sequence. Primers, listed in Tables 1, 2 and 3, were designed to amplify the conserved orthologous regions for Clock1, Clock3, and NPAS2 copies in rainbow trout, Arctic charr and Atlantic salmon. amh sequences were not obtained in this study, but primers designed from known rainbow trout amh EST sequences were used to detect SSCP polymorphisms within this gene (see below).

Polymerase chain reactions (PCR) consisted of $150 \mathrm{ng}$ of genomic DNA, $1 \times$ PCR buffer (Invitrogen), $1.5 \mathrm{mM}$ MgSO4, 0.2-0.4 $\mu \mathrm{M}$ primer mix, $0.2 \mathrm{mM}$ of each dNTP (Fisher Scientific) and $1 \mathrm{U}$ of High Fidelity Platinum Taq polymerase (Invitrogen). The thermal cycler conditions were as follows: denaturation at $94^{\circ} \mathrm{C}$ for $1 \mathrm{~min}$ that was followed by 35 amplification cycles of $94^{\circ} \mathrm{C}$ for $30 \mathrm{~s}, 48-62^{\circ} \mathrm{C}$ for $30 \mathrm{~s}$ and $68^{\circ} \mathrm{C}$ for $1-10 \mathrm{~min}(1 \mathrm{~min}$ per $\mathrm{Kbp})$. The amplification products were observed on 1.02.0\% TBE agarose gel and purified using Qiaquick Gel Extraction Kit (Qiagen) and inserted into pGEM Easy Vector (Promega). The plasmid DNA from six clones for each PCR product was purified (QIAprep Plasmid Miniprep Kit, Qiagen) and sequenced with T7 and Sp6 primers and the Big Dye Terminator Cycle Sequencing Ready Reaction Kit on the ABI 3730 DNA analyzer (Applied Biosystems, Foster City, California, USA).

\section{Sequence analysis of Salmonine Clock genes}

Basic Local Alignment (BLASTN) [122] searches were used to confirm the identity of the Clock sequences. Sequence identity values were determined by pairwise comparisons of the salmonine Clock sequences using the Jukes-Cantor correction in MEGA 4.0 [123]. Additional nucleotide and protein alignments were generated by hand using BioEdit Sequence Alignment Editor [124]. Rainbow trout, Atlantic salmon, and Arctic charr Clock exons were named based on homology to either Chinook salmon Clock1a (Otsclock1a) exons or zebrafish Clock (DreClock1; AF133306) exons. Clock1b sequences were aligned with DreClock1 exons to determine coding regions. Since Otsclock1b (DQ780894) from Chinook salmon has only been partially sequenced the exons were not annotated, and thus reference is made to the orthologous exon blocks in zebrafish. NPAS2 exons were determined by alignment with NPAS2 (Ensembl: ENSGACG00000020338) from stickleback. Sequencing and mapping primers for the genes investigated in this study, along with their GenBank accession numbers are provided in Tables 1, 2 and 3 for rainbow trout, Atlantic salmon, and Arctic charr, respectively.

\section{Phylogenetic analysis of teleost Clock genes}

The coding regions from the 3' end of Clock1 from medaka (Ensembl: ENSGACG000000; exon 18-21), zebrafish (exon 16-19), Chinook salmon (Otsclock1a: exon 16-19; Otsclock1b: exon 16-19), rainbow trout (OmyClock1a: exon 16-19; OmyClock1b: exon 16-19), Atlantic salmon (SsaClock1b: exon 16-19), and Arctic charr 
Table 1 Primer sequences, purpose, annealing temperature (TA), number of bands and product size for primers during PCR, accession number and the linkage groups (LG) where the fragments were localized in rainbow trout

\begin{tabular}{|c|c|c|c|c|c|c|c|c|}
\hline $\begin{array}{l}\text { Primer } \\
\text { Name }\end{array}$ & Primer Sequence $\left(5^{\prime} \rightarrow 3^{\prime}\right)$ & & TA & $\begin{array}{c}\text { \# of Bands Band } \\
\text { size }\end{array}$ & $\begin{array}{c}\text { Sequence Name (GB } \\
\text { Accession \#) }\end{array}$ & $\begin{array}{c}\text { Family \& } \\
\text { parent }\end{array}$ & LG & $\overline{\text { Arm }}$ \\
\hline \multirow[t]{2}{*}{ Clock1a } & 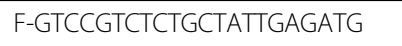 & Sequencing & 61 & 2 & OmyClock1a & & & \\
\hline & R-AGTCACCAGCTTAGTCAGCAAC & & & $1.5 \mathrm{~kb}, 2.5 \mathrm{~kb}$ & (GU228520) & & & \\
\hline \multirow[t]{2}{*}{ Clock1a-1 } & F-CCCAGTGTCCAGGTGAGAAA & Mapping & 57 & & & 4490 & 8 & c \\
\hline & R-CCTITGTTCAGGGACACATT & & & & & & & \\
\hline \multirow[t]{2}{*}{ Clock1a-2 } & F-ACCCTGGGCATCTITCTITT & Mapping & 57 & & & $25 \% 0^{\pi}$ & 8 & c \\
\hline & R-GGAAAACTGTACCATGGGCTA & & & & & & & \\
\hline \multirow[t]{2}{*}{ Clock1b } & F-ACCCAGAATACAGGGCAGAAC & Sequencing & 51 & 2 & OmyClock1b & & & \\
\hline & R-CAGGATCAATTGAGTGGACTGG & & & $1.5 \mathrm{~kb}, 1.3 \mathrm{~kb}$ & (GU228521) & & & \\
\hline \multirow[t]{2}{*}{ Clock1b-1 } & F-AACATGGCCCCTTCCATT & Mapping & 60 & & & $250^{n}$ & 24 & $p$ \\
\hline & R-TCTCACCTGGACACTGGACA & & & & & 449 & 24 & $\mathrm{p}$ \\
\hline \multirow[t]{2}{*}{ Clock3 } & F-TTGGAAAGGGTAAATCCTGCT & Sequencing & 51 & 2 & OmyClock3 & & & \\
\hline & R-CTCGCACCTCCGCATAACT & & & $660 \mathrm{bp}, 426 \mathrm{bp}$ & (GU228522) & & & \\
\hline \multirow[t]{2}{*}{ Clock3-1 } & F-CACCAGTGGAACTCCAAGC & Mapping & 61 & & & $250^{\pi}$ & 20 & $\mathrm{p}$ \\
\hline & R-CGCACCTCCGCATAACTACA & & & & & & & \\
\hline \multirow[t]{2}{*}{ NPAS2 } & F-TGCAGTTTGGAAAGGGTAAA & Sequencing & 51 & 2 & OmyNPAS2 & & & \\
\hline & R-GAAGTGGCCATGTCAGGTG & & & 602 bp, 487 bp & (GU228523) & & & \\
\hline \multirow[t]{2}{*}{ NPAS2-1 } & F-TTGGAAAGGGTAAATCCTGCT & Mapping & 61 & & & $25 \%$ & 9 & $\mathrm{p}$ \\
\hline & R-GCCAGATCTITCTTCAAGACG & & & & & & & \\
\hline \multirow[t]{2}{*}{ Amh } & F-ACTCCTCCATGTGGTGCAA & Mapping & & & & $25 \% 0^{\pi}$ & 8 & c \\
\hline & R-CCATACAGTCTTATCTGATCATGC & & & & & $4490^{\pi}$ & & \\
\hline
\end{tabular}

(SalClock1a: exon 16-19), Clock3 sequences from zebrafish (Ensembl: ENSDARG00000003631; exon 16-19), and NPAS2 sequences from medaka (Ensembl: ENSGACG00000020338; exon 17-20) and zebrafish (Ensembl:ENSDARG00000016536; exon 16-20) were aligned using CLUSTALW [125]. Phylogenetic trees were constructed using the neighbor-joining algorithm for distances and maximum parsimony criteria in MEGA4 [123] at default settings. The MP tree was rooted to the medaka OlaClock sequence. The robustness of the tree topology was determined by bootstrap analysis with 1000 replicates.

\section{Mapping of Clock and amh genes}

To localize the Clock genes in the rainbow trout, Arctic charr, and Atlantic salmon linkage maps, copy-specific primers were developed to amplify family-based polymorphic insertion-deletion or single nucleotide regions (SNPs) in the sequences (Tables 1, 2 and 3). Anti-müllerian hormone $(a m h)$ primers were developed from a

Table 2 Primer sequences, purpose, annealing temperature (TA), number of bands and product size for primers during PCR, accession number and the linkage groups (LG) where the fragments were localized in Atlantic salmon

\begin{tabular}{|c|c|c|c|c|c|c|c|c|}
\hline $\begin{array}{l}\text { Primer } \\
\text { Name }\end{array}$ & Primer Sequence $\left(5^{\prime} \rightarrow 3^{\prime}\right)$ & & $\mathrm{T}_{\mathrm{A}}$ & $\begin{array}{c}\text { \# of Bands Band } \\
\text { size }\end{array}$ & $\begin{array}{l}\text { Sequence Name (GB } \\
\text { Accession \#) }\end{array}$ & $\begin{array}{c}\text { Family \& } \\
\text { parent }\end{array}$ & LG & Arm \\
\hline \multirow[t]{2}{*}{ Clock1a-1 } & F-CCCAGTGTCCAGGTGAGAAA & Mapping & 57 & & & BR5 9 & 2 & qa \\
\hline & R-CCTITGTTCAGGGACACATT & & & & & & & \\
\hline \multirow[t]{2}{*}{ Clock1a-2 } & F-ACCCTGGGCATCTTTCTITT & Mapping & 57 & & & BR50 & 2 & qa \\
\hline & R-GGAAAACTGTACCATGGGCTA & & & & & & & \\
\hline \multirow[t]{2}{*}{ Clock1b } & F-ACCCAGAATACAGGGCAGAAC & Sequencing & 51 & 2 & SsaClock1b & & & \\
\hline & R-CAGGATCAATTGAGTGGACTGG & & & $1.5 \mathrm{~kb}, 1.3 \mathrm{~kb}$ & (GU228525) & & & \\
\hline \multirow[t]{2}{*}{ Clock1b-2 } & F-GGTGCAGATGTTCCTCCAA & Mapping & 57 & & & BR69 & 18 & q \\
\hline & R-TCACAGAAGACTGTGAGAGGAC & & & & & & & \\
\hline \multirow[t]{2}{*}{ Clock1b-3 } & F-GAGTACTGCCCTGCAGGTTG & Mapping & 55 & & & BR5O & 18 & q \\
\hline & R-TTGACCATGGCCCTCTTATG & & & & & & & \\
\hline \multirow[t]{2}{*}{ NPAS2-2 } & F-CCTCCTGAGGGGGAGAAAG & Mapping & 55 & & & BR69 & 5 & $q b$ \\
\hline & R-GAAGTGGCCATGTCAGGTG & & & & & & & \\
\hline
\end{tabular}


Table 3 Primer sequences, purpose, annealing temperature (TA), number of bands and product size for primers during PCR, accession number and the linkage groups (LG) where the fragments were localized in Arctic charr

\begin{tabular}{|c|c|c|c|c|c|c|c|}
\hline $\begin{array}{l}\text { Primer } \\
\text { Name }\end{array}$ & Primer Sequence $\left(5^{\prime} \rightarrow 3^{\prime}\right)$ & & $\mathrm{T}_{\mathrm{A}}$ & $\begin{array}{c}\text { \# of Bands Band } \\
\text { size }\end{array}$ & $\begin{array}{c}\text { Sequence Name (GB Accession } \\
\#)\end{array}$ & $\begin{array}{c}\text { Family \& } \\
\text { parent }\end{array}$ & LG \\
\hline \multirow[t]{2}{*}{ Clock1a-1 } & F-CCCAGTGTCCAGGTGAGAAA & Mapping & 57 & & & 39 & 16 \\
\hline & R-CCTITGTTCAGGGACACATT & & & & & & \\
\hline \multirow[t]{2}{*}{ Clock1b } & F-ACCCAGAATACAGGGCAGAAC & Sequencing & 51 & 2 & SalClock1b & & \\
\hline & R-CAGGATCAATTGAGTGGACTGG & & & $1.5 \mathrm{~kb}, 1.3 \mathrm{~kb}$ & (GU228524) & & \\
\hline \multirow[t]{2}{*}{ Clock1b-3 } & F-GAGTACTGCCCTGCAGGTTG & Mapping & 55 & & & $30^{*}$ & 13 \\
\hline & R-TTGACCATGGCCCTCTTATG & & & & & & \\
\hline \multirow[t]{2}{*}{ NPAS2-3 } & F-CTTATAATCTCCACCCAGCACA & Mapping & 61 & & & 29 & 43 \\
\hline & R-GTCCGTGACAGAGTGCGATA & & & & & $30^{\circ}$ & 20 \\
\hline \multirow[t]{2}{*}{ amh } & F-ACTCCTCCATGTGGTGCAA & Mapping & & & & 29 & 13 \\
\hline & R-CCATACAGTCTTATCTGATCATGC & & & & & $3 \%$ & 13 \\
\hline
\end{tabular}

rainbow trout EST contig cluster TC133387 deposited in the Harvard DFCI gene indices [126]. Polymerase chain reactions were performed in $7 \mu \mathrm{L}$ reaction volumes consisting of $30 \mathrm{ng}$ of template DNA, $1 \times$ PCR buffer (Promega), $0.2 \mathrm{mM}$ each dNTP (Fisher Scientific), $0.1 \mu \mathrm{M}$ of each primer (one of the primers being 5 'fluorescently end-labeled with tetrachloro-6-carboxyfluorescein (TET)), $2 \mathrm{mM} \mathrm{MgCl}_{2}$ (Promega) and $0.15 \mathrm{U}$ of the GoTaq DNA polymerase (Promega). The amplifications were performed on a Peltier Thermal Cycler PTC-200 (MJ Research, MA) with the conditions as follows: initial denaturation at $94^{\circ} \mathrm{C}$ for $4 \mathrm{~min}$ followed by 35 amplification cycles of $94^{\circ} \mathrm{C}$ for $20 \mathrm{~s}, 48-62^{\circ} \mathrm{C}$ for 20 $\mathrm{s}$ and $72^{\circ} \mathrm{C}$ for $30 \mathrm{~s}$. The amplification products were run on $6 \%$ acrylamide gels for length polymorphisms [31] or single-stranded conformational polymorphism (SSCP) gels for SNPs [8]. The gels were visualized on a FMBIO III scanner and Image Analysis software (Hitachi Genetics Systems). After genotyping the mapping families, LINKMFEX [127] was used to test for deviations from the Mendelian segregation ratio of markers (1:1, log-likelihood G-test) and determine the linkage ordering of markers within specific linkage group assignments using a minimum logarithm of odds score of 4.0 .

\section{Analysis of mapping locations: comparative genomics and QTL}

The mapping positions of Clock duplicates within a given species were used to indicate homeologous affinities between linkage groups. As well, the mapping positions of Clock orthologs across the salmonine species were compared to determine homologies. Comparative synteny analyses between the salmonines and model fish species, zebrafish, stickleback, and medaka, were used to determine the ancient origin of the genomic regions surrounding the Clock and amh genes. To assess homologies among the three model teleost species, rainbow trout Clock and NPAS2 sequences were aligned to the genomes of these two species using two approaches. First, BLASTN alignments using the "Distant Homologies" option in http://www. ensembl.org were utilized to assess the most likely contiguous alignments of these sequences to those of the three model species. Second, MEGABLAST [122] was used to search for possible widely gapped alignments to the source model species genomes using the "discontiguous alignments" option. If BLAST alignments suggested homology to a genomic region within any one of the model species that did not correspond to an annotated gene description within the species, the genomic region within that species was further queried for possible gene exon structure using the Softberry program Fgenesh-M $[57,128]$, also contained within the Molquest site[129]. Matches to BLASTN alignments that corresponded to possible exon structure reads with Fgenesh-M were interpreted as possible functional genes that are currently unannotated, while lack of identified exon structure within the region was interpreted as a pseudogene signature. Ancient linkage groups are named as per Kasahara et al. [55] and Danzmann et al. [25]. The mapping locations of the Clock genes and amh were also compared to previously known life-history and growth quantitative trait loci (QTL) in the salmonine species.

\section{Synteny analysis of Clock and amh genes}

The strand orientation and chromosomal position of genes upstream and downstream to Clock and amh in zebrafish, medaka, fugu, tetraodon, human, and mouse were determined manually from the gene orientations listed in BIOMART from the Ensembl database [130]. Synteny rearrangements were assessed within homologous linkage group segments using conserved anchor gene positions upstream and downstream of the Clock and amh mapping locations. Anchor gene positions that 
were classified as either major sexual development genes or cell-cycling genes were noted.

\section{Additional material}

Additional file 1: Nucleotide sequence alignment of intron 15/16 of
Omyclock1a and Salmo salar Tc1-like transposons DTSsa5.
Additional file 2: Schematic diagram of conserved syntenic
chromosomal regions adjacent to Clock and anti-müllerian
hormone (amh) genes in medaka (Oryzias latipes), green-spotted
pufferfish (Tetraodon nigroviridis), zebrafish (Danio rerio), fugu
(Takifugu rubripes), mouse (Mus musculus), and humans (Homo
sapiens).

\section{Acknowledgements}

The authors wish to thank Xia Yue for her laboratory assistance throughout the course of this study. The research was supported by the Natural Sciences and Engineering Research Council of Canada through Discovery and Strategic Project Grants to RGD and MMF.

\section{Author details}

${ }^{1}$ Department of Integrative Biology, University of Guelph, Guelph, Ontario, N1G 2W1, Canada. ${ }^{2}$ College of Veterinary Medicine, Cornell University, Ithaca, New York, USA.

\section{Authors' contributions}

Manuscript construction and bioinformatics analyses were preformed by MIP and RGD, while sequencing studies were done by MIP, along with help from HKM. Genotyping analyses were conducted by MIP and HKM. MMF and RGD conceptualized the study. All authors read and commented on the manuscript.

\section{Competing interests}

The authors declare that they have no competing interests.

Received: 14 June 2010 Accepted: 29 July 2010 Published: 29 July 2010

\section{References}

1. Bell-Pedersen D, Cassone VM, Earnest DJ, Golden SS, Hardin PE, Thomas TL, Zoran MJ: Circadian rhythms from multiple oscillators: lessons from diverse organism. Nat Rev Genet 2005, 6:544-556.

2. Storch KF, Lipan O, Leykin I, Viswanathan N, Davis FC, Wong WH, Weitz CJ: Extensive and divergent circadian gene expression in liver and heart. Nature 2002, 417:78-83.

3. Lowrey PL, Takahashi JS: Mammalian circadian biology: elucidating genome-wide levels of temporal organization. Annu Rev Genomics Hum Genet 2004, 5:407-441.

4. Doi M, Hirayama J, Sassone-Corsi P: Circadian regulator CLOCK is a histone acetyltransferase. Cell 2006, 125:497-508.

5. Beaver LM, Gvakharia BO, Vollintine TS, Hege DM, Stanewsky R, Giebultowicz JM: Loss of circadian clock function decreases reproductive fitness in males of Drosophila melanogaster. Proc Natl Acad Sci USA 2002, 99:2134-2139.

6. Chappell PE, White RS, Mellon PL: Circadian gene expression regulates pulsatile gonadotropin-releasing hormone $(\mathrm{GnRH})$ secretory patterns in the hypothalamic GnRH-secreting GT 1-7 cell line. J Neurosci 2003, 23:11202-11213.

7. Miller BH, Olson SL, Turek FW, Levine JE, Horton TH, Takahashi JS: Circadian clock mutation disrupts estrous cyclicity and maintenance of pregnancy. Curr Biol 2004, 14:1367-1373.

8. Leder EH, Danzmann RG, Ferguson MM: The candidate gene, Clock, localizes to a strong spawning time quantitative trait locus region in rainbow trout. J Hered 2006, 97:74-80

9. O'Malley KG, Camara MD, Banks MA: Candidate loci reveal genetic differentiation between temporally divergent migratory runs of Chinook salmon (Oncorhynchus tshawytscha). Mol Ecol 2007, 16:4930-4941.
10. Rouiller-Fabre V, Carmona S, Merhi RA, Cate R, Habert R, Vigier B: Effect of anti-Mullerian hormone on Sertoli and Leydig cell functions in fetal and immature rats. Endocrinology 1998, 139:1213-1220.

11. Durlinger AL, Visser JA, Themmen AP: Regulation of ovarian function: the role of anti-Mullerian hormone. Reproduction 2002, 124:601-609.

12. Durlinger AL, Gruijters MJ, Kramer P, Karels B, Ingraham HA, Nachtigal MW, Uilenbroek JT, Grootegoed JA, Themmen AP: Anti-Mullerian hormone inhibits initiation of primordial follicle growth in the mouse ovary. Endocrinology 2002, 143:1076-1084.

13. Vigier B, Forest MG, Eychenne B, Bezard J, Garrigou O, Robel P, Josso N: Anti-Mullerian hormone produces endocrine sex reversal of fetal ovaries. Proc Natl Acad Sci USA 1989, 86:3684-3688.

14. Josso N, Racine C, di Clemente N, Rey R, Xavier F: The role of antiMullerian hormone in gonadal development. Mol Cell Endocrinol 1998, 145:3-7

15. Al-Attar L, Noel K, Dutertre M, Belville C, Forest MG, Burgoyne PS, Josso N, Rey R: Hormonal and cellular regulation of Sertoli cell anti-Mullerian hormone production in the postnatal mouse. J Clin Invest 1997, 100:1335-1343

16. The Gene Index Project. [http://compbio.dfci.harvard.edu/cgi-bin/tgi/ gimain.pl?gudb=salmon]

17. Rodriguez-Mari A, Yan YL, Bremiller RA, Wilson C, Canestro C, Postlethwait JH: Characterization and expression pattern of zebrafish Anti-Mullerian hormone (Amh) relative to sox9a, sox9b, and cyp19a1a, during gonad development. Gene Expr Patterns 2005, 5:655-667.

18. Yoshinaga N, Shiraishi E, Yamamoto T, Iguchi T, Abe S, Kitano T: Sexually dimorphic expression of a teleost homologue of Mullerian inhibiting substance during gonadal sex differentiation in Japanese flounder, Paralichthys olivaceus. Biochem Biophys Res Commun 2004, 322:508-513.

19. Miura T, Miura C, Konda Y, Yamauchi K: Spermatogenesis-preventing substance in Japanese eel. Development 2002, 129:2689-2697.

20. Maugers G, Schmitz M: Gene expression profiling during spermatogenesis in early maturing male Atlantic salmon parr testes. Gen Comp Endocrinol 2008, 159:178-187.

21. Guiry A, Flynn D, Hubert S, O'Keeffe AM, LeProvost O, White SL, Forde PF, Davoren P, Houeix B, Smith TJ, Cotter D, Wilkins NP, Cairns MT: Testes and brain gene expression in precocious and adult maturing Atlantic salmon (Salmo salar). BMC Genomics 2010, 11:211.

22. Kluver N, Pfennig F, Pala I, Storch K, Schlieder M, Froschauer A, Gutzeit HO, Schartl M: Differential expression of anti-Mullerian hormone (amh) and anti-Mullerian hormone receptor type II (amhrll) in the teleost medaka. Dev Dynam 2007, 236:271-281.

23. Wang $\mathrm{H}$ : Comparative analysis of teleost fish genomes reveals preservation of different ancient clock duplicates in different fishes. Marine Genomics 2008, 1:69-78.

24. Allendorf FW, Thorgaard GH: Tetraploidy and the evolution of salmonid fishes. Evolutionary Genetics of Fishes Plenum Press, NYTurner BJ 1984, Chap 1:1-46.

25. Danzmann RG, Davidson EA, Ferguson MM, Gharbi K, Koop BF, Hoyheim B, Lien S, Lubieniecki KP, Moghadam HK, Park J, et al: Distribution of ancestral proto-Actinopterygian chromosome arms within the genomes of 4R-derivative salmonid fishes (Rainbow trout and Atlantic salmon). BMC Genomics 2008, 9:557.

26. Moghadam HK, Ferguson MM, Danzmann RG: Comparative genomics and evolution of conserved noncoding elements (CNE) in rainbow trout. BMC Genomics 2009, 10:278.

27. O'Malley KG, Banks MA: Duplicated Clock genes with unique polyglutamine domains provide evidence for nonhomologous recombination in Chinook salmon (Oncorhynchus tshawytscha). Genetica 2008, 132:87-94.

28. Alfaqih MA, Brunelli JP, Drew RE, Thorgaard GH: Mapping of five candidate sex-determining loci in rainbow trout (Oncorhynchus mykiss). BMC Genet 2009, 10:2.

29. Leder EH, Danzmann RG, Ferguson MM: Comparison of GNRH3 genes across salmonid genera. Anim Genet 2004, 35:126-129.

30. Moghadam HK, Ferguson MM, Danzmann RG: Evolution of Hox clusters in Salmonidae: a comparative analysis between Atlantic salmon (Salmo salar) and rainbow trout (Oncorhynchus mykiss). J Mol Evol 2005, 61:636-649. 
31. Moghadam HK, Ferguson MM, Rexroad CE, Coulibaly I, Danzmann RG: Genomic organization of the IGF1, IGF2, MYF5, MYF6 and GRF/PACAP genes across Salmoninae genera. Anim Genet 2007, 38:527-532.

32. Mungpakdee $S$, Seo HC, Angotzi AR, Dong $X$, Akalin A, Chourrout D: Differential evolution of the 13 Atlantic salmon Hox clusters. Mol Biol Evol 2008, 25:1333-1343.

33. de Boer JG, Yazawa R, Davidson WS, Koop BF: Bursts and horizontal evolution of DNA transposons in the speciation of pseudotetraploid salmonids. BMC Genomics 2007, 8:422.

34. Saleem Q, Anand A, Jain S, Brahmachari SK: The polyglutamine motif is highly conserved at the Clock locus in various organisms and is not polymorphic in humans. Hum Genet 2001, 109:136-142.

35. Johnsen A, Fidler AE, Kuhn S, Carter KL, Hoffmann A, Barr IR, Biard C, Charmantier A, Eens $M$, Korsten $P$, et al: Avian Clock gene polymorphism: evidence for a latitudinal cline in allele frequencies. Mol Ecol 2007, 16:4867-4880.

36. O'Malley KG, Banks MA: A latitudinal cline in the Chinook salmon (Oncorhynchus tshawytscha) Clock gene: evidence for selection on PolyQ length variants. Proc Biol Sci 2008, 275:2813-2821.

37. Liedvogel M, Szulkin M, Knowles SC, Wood MJ, Sheldon BC: Phenotypic correlates of Clock gene variation in a wild blue tit population: evidence for a role in seasonal timing of reproduction. Mol Ecol 2009, 18:2444-2456.

38. King DP, Zhao Y, Sangoram AM, Wilsbacher LD, Tanaka M, Antoch MP, Steeves TD, Vitaterna MH, Kornhauser JM, Lowrey PL, et al: Positional cloning of the mouse circadian clock gene. Cell 1997, 89:641-653.

39. Gekakis N, Staknis D, Nguyen HB, Davis FC, Wilsbacher LD, King DP, Takahashi JS, Weitz CJ: Role of the CLOCK protein in the mammalian circadian mechanism. Science 1998, 280:1564-1569.

40. Vitaterna $\mathrm{MH}, \mathrm{Ko} \mathrm{CH}$, Chang AM, Buhr ED, Fruechte EM, Schook A, Antoch MP, Turek FW, Takahashi JS: The mouse Clock mutation reduces circadian pacemaker amplitude and enhances efficacy of resetting stimuli and phase-response curve amplitude. Proc Natl Acad Sci USA 2006, 103:9327-9332.

41. Mitchell PJ, Tijan R: Transcriptional regulation in mammalian cells by sequence-specific DNA binding proteins. Science 1989, 245:371-378.

42. Darlington TK, Wager-Smith K, Ceriani MF, Staknis D, Gekakis N, Steeves TD, Weitz CJ, Takahashi JS, Kay SA: Closing the circadian loop: CLOCK-induced transcription of its own inhibitors per and tim. Science 1998, 280:1599-1603.

43. Avivi A, Albrecht U, Oster H, Joel A, Beiles A, Nevo E: Biological clock in total darkness: the Clock/MOP3 circadian system of the blind subterranean mole rat. Proc Natl Acad Sci USA 2001, 98:13751-13756.

44. Haidle L, Janssen JE, Gharbi K, Moghadam HK, Ferguson MM, Danzmann RG: Determination of quantitative trait loci (QTL) for early maturation in rainbow trout (Oncorhynchus mykiss). Mar Biotechnol 2008, 10:579-592.

45. Tuziak SM, Moghadam HK, Danzmann RG: Genetic mapping of the ornithine decarboxylase (ODC) gene complex in rainbow trout (Oncorhynchus mykiss). Cytogenet Genome Res 2009, 125:279-285.

46. Gharbi K, Murray BW, Moghadam HK, Ferguson MM, Wright PA Danzmann RG: Genome organization of glutamine synthetase genes in rainbow trout (Oncorhynchus mykiss). Cytogenet Genome Res 2007, 116:113-115.

47. Phillips RB, Nichols KM, DeKoning JJ, Morasch MR, Keatley KA, Rexroad C, Gahr SA, Danzmann RG, Drew RE, Thorgaard GH: Assignment of rainbow trout linkage groups to specific chromosomes. Genetics 2006, 174:1661-1670

48. Sakamoto T, Danzmann RG, Gharbi K, Howard P, Ozaki A, Khoo SK, Woram RA, Okamoto N, Ferguson MM, Holm LE, et al: A microsatellite linkage map of rainbow trout (Oncorhynchus mykiss) characterized by large sex-specific differences in recombination rates. Genetics 2000, 155:1331-1345.

49. Guyomard R, Mauger S, Tabet-Canale K, Martineau S, Genet C, Krieg F, Quillet E: A type I and type II microsatellite linkage map of rainbow trout (Oncorhynchus mykiss) with presumptive coverage of all chromosome arms. BMC Genomics 2006, 7:302.

50. Rexroad CE, Palti Y, Gahr SA, Vallejo RL: A second generation genetic map for rainbow trout (Oncorhynchus mykiss). BMC Genet 2008, 9:74.

51. Phillips RB, Keatley KA, Morasch MR, Ventura AB, Lubieniecki KP, Koop BF, Danzmann RG, Davidson WS: Assignment of Atlantic salmon (Salmo salar) linkage groups to specific chromosomes: conservation of large syntenic blocks corresponding to whole chromosome arms in rainbow trout (Oncorhynchus mykiss). BMC Genet 2009, 10:46.

52. Woram RA, McGowan C, Stout JA, Gharbi K, Ferguson MM, Hoyheim B, Davidson EA, Davidson WS, Rexroad C, Danzmann RG: A genetic linkage map for Arctic char (Salvelinus alpinus): evidence for higher recombination rates and segregation distortion in hybrid versus pure strain mapping parents. Genome 2004, 47:304-315.

53. Danzmann RG, Cairney M, Davidson WS, Ferguson MM, Gharbi K Guyomard R, Holm LE, Leder E, Okamoto N, Ozaki A, et al: A comparative analysis of the rainbow trout genome with 2 other species of fish (Arctic charr and Atlantic salmon) within the tetraploid derivative Salmonidae family (subfamily: Salmoninae). Genome 2005, 48:1037-1051.

54. Jaillon O, Aury JM, Brunet F, Petit JL, Stange-Thomann N, Mauceli E, Bouneau L, Fischer C, Ozouf-Costaz C, Bernot A, et al: Genome duplication in the teleost fish Tetraodon nigroviridis reveals the early vertebrate proto-karyotype. Nature 2004, 431:946-957.

55. Kasahara M, Naruse K, Sasaki S, Nakatani Y, Qu W, Ahsan B, Yamada T, Nagayasu $Y$, Doi K, Kasai $Y$, et al: The medaka draft genome and insights into vertebrate genome evolution. Nature 2007, 447:714-719.

56. Nakatani $Y$, Takeda H, Kohara Y, Morishita S: Reconstruction of the vertebrate ancestral genome reveals dynamic genome reorganization in early vertebrates. Genome Res 2007, 17:1254-1265.

57. Solovyev V, Kosarev P, Seledsov I, Vorobyev D: Automatic annotation of eukaryotic genes, pseudogenes and promoters. Genome Biol 2006, 7(Suppl 1):S10.1-12.

58. Sakamoto T, Danzmann RG, Okamoto N, Ferguson MM, Ihssen PE: Linkage analysis of quantitative trait loci associated with spawning time in rainbow trout (Oncorhynchus mykiss). Aquaculture 1999, 173:33-43.

59. Martyniuk C, Perry GML, Moghadam HK, Ferguson MM, Danzmann RG: The genetic architecture of correlation among growth related traits and male age at maturation in rainbow trout. J Fish Biol 2003, 63:746-764.

60. O'Malley KG, Sakamoto T, Danzmann RG, Ferguson MM: Quantitative trait loci for spawning date and body weight in rainbow trout: testing for conserved effects across ancestrally duplicated chromosomes. J Hered 2003, 94:273-284.

61. Sundin K, Brown K, Drew RE, Nichols K, Wheeler PE, Thorgaard GH: Genetic analysis of a development rate QTL in backcrosses of clonal rainbow trout, Oncorhynchus mykiss. Aquaculture 2005, 247:75-83.

62. Fotherby $\mathrm{H}$ : Detection of quantitative trait loci for age at sexual maturation in North American Atlantic salmon (Salmo salar). M Sc Thesis University of Guelph 2007.

63. Moghadam HK, Poissant J, Fotherby H, Haidle L, Ferguson MM, Danzmann RG: Quantitative trait loci for body weight, condition factor and age at sexual maturation in Arctic charr (Salvelinus alpinus): comparative analysis with rainbow trout (Oncorhynchus mykiss) and Atlantic salmon (Salmo salar). Mol Genet Genomics 2007, 277:647-661.

64. Nichols KM, Broman KW, Sundin K, Young JM, Wheeler PA, Thorgaard GH: Quantitative trait loci $x$ maternal cytoplasmic environment interaction for development rate in Oncorhynchus mykiss. Genetics 2007, 175:335-347.

65. Nichols KM, Edo AF, Wheeler PA, Thorgaard GH: The genetic basis of smoltification-related traits in Oncorhynchus mykiss. Genetics 2008 179:1559-1575

66. Wringe BF, Devlin RH, Ferguson MM, Moghadam HK, Sakhrani D, Danzmann RG: Growth-related quantitative trait loci in domestic and wild rainbow trout (Oncorhynchus mykiss). BMC Genet 2010, 11:63.

67. Overbeek R, Fonstein M, D'Souza M, Pusch GD, Maltsev N: The use of gene clusters to infer functional coupling. Proc Natl Acad Sci USA 1999, 96:2896-2901.

68. Yan J, Wang H, Liu Y, Shao C: Analysis of gene regulatory networks in the mammalian circadian rhythm. PLoS Comp Biol 2008, 4:e1000193.

69. Birk OS, Casiano DE, Wassif CA, Cogliati T, Zhao L, Zhao Y, Grinberg A, Huang SP, Kreidberg JA, Parker KL, et al: The LIM homeobox gene Lhx9 is essential for mouse gonadal development. Nature 2000, 403:909-913.

70. Mazaud S, Oreal E, Guigon CJ, Carre-Eusebe D, Magne S: Lhx9 expression during gonadal morphogenesis as related to the state of cell differentiation. Gene Expr Patterns 2002, 2:373-377.

71. Choi Y, Ballow DJ, Xin Y, Rajkovic A: Lim homeobox gene, Ihx8, is essential for mouse oocyte differentiation and survival. Biol Reprod 2008, 79:442-449. 
72. Duggavathi R, Volle DH, Mataki C, Antal MC, Messaddeq N, Auwerx J, Murphy BD, Schoonjans K: Liver receptor homolog 1 is essential for ovulation. Genes Dev 2008, 22:1871-1876.

73. Fayard E, Auwerx J, Schoonjans K: LRH-1: an orphan nuclear receptor involved in development, metabolism and steroidogenesis. Trends Cell Biol 2004, 14:250-260.

74. Kusakabe M, Nakamura I, Young G: 11beta-Hydroxysteroid Dehydrogenase Complementary Deoxyribonucleic Acid in Rainbow Trout: Cloning, Sites of Expression, and Seasonal Changes in Gonads. Endocrinology 2003, 144:2534-2545

75. Miura T, Miura Cl: Molecular control mechanisms of fish spermatogenesis. Fish Physiol Biochem 2003, 28:181-186

76. Devlin $\mathrm{RH}$, Nagahama $\mathrm{Y}$ : Sex determination and sex differentiation in fish: an overview of genetic, physiological, and environmental influences. Aquaculture 2002, 208:191-364.

77. Bilbao JR, Loridan L, Audi L, Gonzalo E, Castano L: A novel missense (R80W) mutation in 17-beta-hydroxysteroid dehydrogenase type 3 gene associated with male pseudohermaphroditism. Eur J Endocrinol 1998, 139:330-333.

78. Agarwal AK, Mune T, Monder C, White PC: NAD(+)-dependent isoform of 11 beta-hydroxysteroid dehydrogenase. Cloning and characterization of cDNA from sheep kidney. J Biol Chem 1994, 269:25959-25962.

79. Monder C, Miroff Y, Marandici A, Hardy MP: 11 beta-Hydroxysteroid dehydrogenase alleviates glucocorticoid-mediated inhibition of steroidogenesis in rat Leydig cells. Endocrinology 1994, 134:1199-1204.

80. Fenske M: Role of cortisol in the $\mathrm{ACTH}$-induced suppression of testicular steroidogenesis in guinea pigs. J Endocrinol 1997, 154:407-414.

81. Gao HB, Tong MH, Hu YQ, Guo QS, Ge R, Hardy MP: Glucocorticoid induces apoptosis in rat leydig cells. Endocrinology 2002, 143:130-138.

82. Ashman LK: The biology of stem cell factor and its receptor C-kit. Int J Biochem Cell Biol 1999, 31:1037-1051.

83. Magnol L, Chevallier MC, Nalesso V, Retif S, Fuchs H, Klempt M, Pereira P, Riottot M, Andrzejewski S, Doan BT, et al: KIT is required for hepatic function during mouse post-natal development. BMC Dev Biol 2007, 7:81.

84. Sette C, Dolci S, Geremia R, Rossi P: The role of stem cell factor and of alternative c-kit gene products in the establishment, maintenance and function of germ cells. Int J Dev Biol 2000, 44:599-608

85. Hutt KJ, McLaughlin EA, Holland MK: Kit ligand and c-Kit have diverse roles during mammalian oogenesis and folliculogenesis. Mol Hum Reprod 2006, 12:61-69.

86. Yamamoto K, Tojo A, Aoki N, Shibuya M: Characterization of the promoter region of the human c-kit proto-oncogene. Jpn J Cancer Res 1993, 84:1136-1144.

87. Shirai H, Oishi K, Ishida N: Bidirectional CLOCK/BMAL1-dependent circadian gene regulation by retinoic acid in vitro. Biochem Biophys Res Commun 2006, 351:387-391.

88. Carlson DR, Williams DE: Sex-specific vitellogenin production in immature rainbow trout. Environ Toxicol Chem 1999, 18:2361-2363.

89. Nakao N, Yasuo S, Nishimura A, Yamamura T, Watanabe T, Anraku T, Okano T, Fukada Y, Sharp PJ, Ebihara S, et al: Circadian clock gene regulation of steroidogenic acute regulatory protein gene expression in preovulatory ovarian follicles. Endocrinology 2007, 148:3031-3038.

90. Takada S, Wada T, Kaneda R, Choi YL, Yamashita Y, Mano H: Evidence for activation of Amh gene expression by steroidogenic factor 1. Mech Dev 2006, 123:472-480

91. Halm S, Rocha A, Miura T, Prat F, Zanuy S: Anti-mullerian hormone (AMH/ $\mathrm{AMH})$ in the European sea bass: Its structure, regulatory elements, and the expression of alternatively-spliced isoforms. Gene 2007, 388:148-158.

92. Benoit G, Cooney A, Giguere V, Ingraham H, Lazar M, Muscat G, Perlmann T, Renaud JP, Schwabe J, Sladek F, et al: International Union of Pharmacology. LXVI. Orphan nuclear receptors. Pharmacol Rev 2006, 58:798-836.

93. Carleton M, Mao M, Biery M, Warrener P, Kim S, Buser C, Marshall CG, Fernandes C, Annis J, Linsley PS: RNA interference-mediated silencing of mitotic kinesin KIF14 disrupts cell cycle progression and induces cytokinesis failure. Mol Cell Biol 2006, 26:3853-3863.

94. San-Segundo PA, Roeder GS: Role for the silencing protein Dot1 in meiotic checkpoint control. Mol Biol Cell 2000, 11:3601-3615.

95. Wysocki R, Javaheri A, Allard S, Sha F, Cote J, Kron SJ: Role of Dot1dependent histone $\mathrm{H} 3$ methylation in $\mathrm{G} 1$ and $\mathrm{S}$ phase DNA damage checkpoint functions of Rad9. Mol Cell Biol 2005, 25:8430-8443.
96. Jones B, Su H, Bhat A, Lei H, Bajko J, Hevi S, Baltus GA, Kadam S, Zhai H, Valdez $\mathrm{R}$, et al: The histone H3K79 methyltransferase Dot1L is essential for mammalian development and heterochromatin structure. PLOS Genet 2008, 4:e1000190.

97. Oredsson SM: Polyamine dependence of normal cell-cycle progression. Biochem Soc Trans 2003, 31:366-370

98. Nasizadeh S, Myhre L, Thiman L, Alm K, Oredsson S, Persson L: Importance of polyamines in cell cycle kinetics as studied in a transgenic system. Exp Cell Res 2005, 308:254-264.

99. Ivanov IP, Pittman AJ, Chien CB, Gesteland RF, Atkins JF: Novel antizyme gene in Danio rerio expressed in brain and retina. Gene 2007, 387:87-92.

100. Linder P: Dead-box proteins: a family affair-active and passive players in RNP-remodeling. Nucleic Acids Res 2006, 34:4168-4180.

101. Pascual-Le Tallec L, Simone F, Viengchareun S, Meduri G, Thirman MJ, Lombes M: The elongation factor ELL (eleven-nineteen lysine-rich leukemia) is a selective coregulator for steroid receptor functions. $\mathrm{Mol}$ Endocrinol 2005, 19:1158-1169.

102. Teboul M, Guillaumond F, Grechez-Cassiau A, Delaunay F: The nuclear hormone receptor family round the Clock. Mol Endocrinol 2008, 22:2573-2582.

103. Ng YK, Wu W, Zhang L: Positive correlation between gene coexpression and positional clustering in the zebrafish genome. BMC Genomics 2009, 10:42.

104. Panda S, Antoch MP, Miller BH, Su Al, Schook AB, Straume M, Schultz PG, Kay SA, Takahashi JS, Hogenesch JB: Coordinated transcription of key pathways in the mouse by the circadian clock. Cell 2002, 109:307-320.

105. Resuehr D, Wildemann U, Sikes $H$, Olcese J: E-box regulation of gonadotropin-releasing hormone $(\mathrm{GnRH})$ receptor expression in immortalized gonadotrope cells. Mol Cell Endocrinol 2007, 278:36-43.

106. Gronemeyer H, Gustafsson JA, Laudet V: Principles for modulation of the nuclear receptor superfamily. Nat Rev Drug Discov 2004, 3:950-964.

107. Pettersson K, Gustafsson JA: Role of estrogen receptor beta in estrogen action. Annu Rev Physiol 2001, 63:165-192.

108. Cai W, Rambaud J, Teboul M, Masse I, Benoit G, Gustafsson J-A, Delaunay F, Laudet $V$, Pongratz I: Expression levels of estrogen receptor $\beta$ are modulated by components of the molecular clock. Mol Cell Biol 2008, 28:784-793.

109. Alvarez JD, Hansen A, Ord T, Bebas P, Chappell PE, Giebultowicz JM, Williams C, Moss S, Sehgal A: The circadian clock protein BMAL1 is necessary for fertility and proper testosterone production in mice. J Biol Rhythms 2008, 23:26-36.

110. Matsuo T, Yamaguchi S, Mitsui S, Emi A, Shimoda F, Okamura H: Control mechanism of the circadian clock for timing of cell division in vivo. Science 2003, 302:255-259.

111. Hunt T, Sassone-Corsi P: Riding tandem: circadian clocks and the cell cycle. Cell 2007, 129:461-464.

112. Fu L, Pelicano H, Liu J, Huang P, Lee C: The circadian gene Period2 plays an important role in tumor suppression and DNA damage response in vivo. Cell 2002, 111:41-50.

113. Hoffman AE, Zheng T, Ba Y, Zhu Y: The circadian gene NPAS2, a putative tumor suppressor, is involved in DNA damage response. Mol Cancer Res 2008, 6:1461-1468.

114. Chaudhary J, Skinner MK: E-box and cyclic adenosine monophosphate response elements are both required for follicle-stimulating hormoneinduced transferrin promoter activation in Sertoli cells. Endocrinology 1999, 140:1262-1271

115. Yan C, Elvin JA, Lin YN, Hadsell LA, Wang J, DeMayo FJ, Matzuk MM: Regulation of growth differentiation factor 9 expression in oocytes in vivo: a key role of the E-box. Biol Reprod 2006, 74:999-1006.

116. Scobey MJ, Fix CA, Walker WH: The Id2 transcriptional repressor is induced by follicle-stimulating hormone and CAMP. J Biol Chem 2004, 279:16064-16070.

117. Woodson KG, Crawford PA, Sadovsky Y, Milbrandt J: Characterization of the promoter of SF-1, an orphan nuclear receptor required for adrenal and gonadal development. Mol Endocrinol 1997, 11:117-126.

118. Miller BH, Olson SL, Levine JE, Turek FW, Horton TH, Takahashi JS: Vasopressin regulation of the proestrous luteinizing hormone surge in wild-type and Clock mutant mice. Biol Reprod 2006, 75:778-784.

119. Kowase T, Walsh HE, Darling DS, Shupnik MA: Estrogen enhances gonadotropin-releasing hormone-stimulated transcription of the 
luteinizing hormone subunit promoters via altered expression of stimulatory and suppressive transcription factors. Endocrinology 2007, 148:6083-6091.

120. Nichols KM, Young WP, Danzmann RG, Robison BD, Rexroad C, Noakes M, Phillips RB, Bentzen P, Spies I, Knudsen K, et al: A consolidated linkage map for rainbow trout. (Oncorhynchus mykiss) Anim Genet 2003, 34:102-115.

121. Genomic Research on Atlantic Salmon Project. [http://grasp.mbb.sfu.ca/ BlastServer/blast/blast.html]

122. National Centre for Biotechnology Information. [http://blast.ncbi.nlm.nih. gov/Blast.cgi].

123. Tamura K, Dudley J, Nei M, Kumar S: MEGA4: Molecular Evolutionary Genetics Analysis (MEGA) software version 4.0. Mol Biol Evol 2007, 24:1596-1599

124. Hall T: BioEdit: a user-friendly biological sequence alignment editor and analysis program for Windows 95/98/NT. Nucleic Acids Symposium Series 1999, 41:95-98.

125. Thompson JD, Higgins DG, Gibson TJ: CLUSTAL W: improving the sensitivity of progressive multiple sequence alignment through sequence weighting, position-specific gap penalties and weight matrix choice. Nucleic Acids Res 1994, 22:4673-4680.

126. The Gene Index Project. [http://compbio.dfci.harvard.edu/tgi/cgi-bin/tgi/ gimain.pl?gudb=r_trout].

127. University of Guelph Faculty Pages. [http://www.uoguelph.ca/ rdanzman/ software].

128. Softberry. [http://linux1.softberry.com/berry.phtml?topic=fgeneshm\&group $=$ programs\&subgroup $=$ gfind] .

129. Molquest. [http://www.molquest.com/molquest.phtml? group=index\&topic=gfind].

130. Ensembl. [http://www.ensembl.org/biomart/martview/].

doi:10.1186/1756-0500-3-215

Cite this article as: Paibomesai et al:: Clock genes and their genomic distributions in three species of salmonid fishes: Associations with genes regulating sexual maturation and cell cycling. BMC Research Notes 2010 3:215.

\section{Submit your next manuscript to BioMed Central and take full advantage of:}

- Convenient online submission

- Thorough peer review

- No space constraints or color figure charges

- Immediate publication on acceptance

- Inclusion in PubMed, CAS, Scopus and Google Scholar

- Research which is freely available for redistribution

Submit your manuscript at www.biomedcentral.com/submit 